\title{
Renewable Energy Scenario and Environmental Aspects of Soil Emission Measurements
}

\section{Ahmed Al Makky. ${ }^{1}$, A.Alaswad ${ }^{2}$, Desmond.Gibson ${ }^{3}$ and A.G.Olabi ${ }^{4}$}

1. School of Engineering, University of the West of Scotland, Paisley: email: Ahmed.AlMakky@uws.ac.uk

2. School of Engineering, University of the West of Scotland, Paisley; email: Abed.Alaswad@uws.ac.uk

3. Scottish Universities Physics Alliance, Institute of Thin Films, Sensors \& Imaging: Des.Gibson@uws.ac.uk

4. School of Engineering, University of the West of Scotland, Paisley; email: Abdul.Olabi@uws.ac.uk

\begin{abstract}
European Commission has set clear targets for 2020 regarding energy and environment policy; these targets include $20 \%$ cut in greenhouse gas emissions against the 1990 levels. It is believed that adopted strategy has encouraged the renewable energy applications during the last two decades. Moreover, measurement deviations of carbon dioxide flux occurring in respiration chambers has been seen of a great importance to explain the biochemical parameters affecting the climate change issue. This is attributed on many occasions to chamber design constraints and the way they are coupled with the studied site location. This is illustrated by external disturbances whereby when they happen while gas measurements are
\end{abstract}


taken measurement deviations become more evident. This paper surveys the different soil physical, biological and geotechnical parameters and links them to meteorological ones. Consequently it explores their direct and indirect effects to the produced soil efflux. Furthermore this paper proposes several soil temperature models according to the studied case constraints to see what affects soil efflux production. Moreover a clear understanding of what affects the measurement process was achieved through surveying all the internal and external pressure parameters and how they influence the chamber in relation to time. The conclusion is that respiration chamber designers need to preserve chamber internal temperature and pressure to be equal to the outer atmosphere for the case of stabile external conditions. For the case of unstable external conditions design counter measures are incorporated. Furthermore the appropriate gas sensor needs to be selected professionally with emphasis on the importance of installation location inside the chamber. Likewise soil bacterial type and soil temperature also has an influence on efflux production.

Keywords: Soil porosity; Respiration chambers; Global warming; Renewable energy; Climate change

\subsection{Introduction}

Soil can be defined as a complex system, consisting of a mixture of organic and mineral particles, soil solution and air, resulting from the interaction between biotic and abiotic factors; it is the medium in which plants acquire water and nutrients through their roots system.

An efflux is something that flows out or forth from a porous medium (Soil) which for our case of concern is carbon dioxide. Carbon dioxide gas in the soil is produced due to the occurring biological activity in the soil domain. Measuring accurately the production of gas species from 
the soil is a complex problem. This is due to the great spatial variability in soil emissions and to the fact that the quantification of these emissions is complicated by the high spatial variability exhibited by many microbial processes [1]. What also enforces the spatial variability is that soil chemical composition varies from one location to another [2]. To quantify the amount of the produced carbon dioxide at one location it is captured in an enclosed cavity or space which can be a chamber. This method was first proposed by Henrik Lundegardh [3] in the form of the respiration bell. In the general context using respiration chambers can give scientists some insight to how fertile the studied site is. That is by measuring the rate of carbon dioxide produced for a certain site of concern and predict its impact on global warming issues [4]. Consequently with the increase of carbon dioxide concentrations in the atmosphere, planet earth responds to it in the form of the green house affect [5]. For instance global warming is attributed to burning excessive amounts of fossil fuels [6] furthermore it is also linked to the rise of human population around the world. Therefore using sustainable sources of energy to support the growing in population nations comes of priority for future, as the study showed for the country of Sudan [7]. Scientist see switching to renewable sources of energy is achievable as shown in the global energy policy study by [8]. To help the gradual introduction and use of solar power governments have set solar energy polices. For instance for a country such as Malaysia the government has set its solar energy policy as mentioned in [9]. Energy planning algorithms for energy resource allocation can also assist in managing renewable energy sources. This is through using Multi-Criteria Decision Making techniques used to take care of multiple, conflicting criteria to arrive at better solutions [10]. Wind forecasting algorithms are also being used for the purpose of managing renewable energy sources, this is based on the assessment of wind power forecasting models done by [11]. Fuel cells are another efficient clean source of energy as mentioned by [12] whereby electrical-generation efficiencies of $70 \%$ where achieved along with a heat recovery possibility. Moreover future 
wise fuel cell based power systems will render an ideal distribution power-generation system characterized to be: reliable, clean, quiet, environmentally friendly, and fuel conserving.

A matter of immediate concern in the hazardous energy situation in most African countries is that forest resources are gradually declining. Hence the supply of fuel wood is becoming more difficult to sustain and demand especially that it is already exceeding the potential supply [13]. Therefore one of the main requirements of green energies is to be characterised as efficient systems furthermore for governments to apply policies that make citizens gradually use less fossil fuels [14]. Consequently new fuels are being introduced to the global market as for example in Malaysia palm oil is considered a sustainable source of fuel particularly that palm oil is one of the most productive bio-diesel crop. Moreover, its waste streams can be used to produce vast amounts of bio-gas and other values added products [15]. Another promising method is to use small scale gasifiers for domestic use in rural areas especially for cooking [16]. Likewise another sustainable type of fuel is ethanol what was evident that more research needs to be applied to get convincing proofs of its environmental friendliness as shown in the comparison between E10 and E0 [17].

In this paper: The required gas sensor type to be used in the respiration chamber is covered furthermore its location of installation inside the chamber is advised. Additionally types of used gas sensors in static and dynamic chambers are surveyed. On the other hand an inner chamber temperature effect on gas sensors is considered in a discussion. For the reason that infrared gas sensors are becoming commonly used in respiration chambers furthermore mentioned is a set of required considerations for gas sensors. Moreover gas sensor calibration methods are covered in particular that no sensor measurement occurs without sensor calibration is performed on a frequent basis. Lastly a recommendation to what types of sensors to be used on chambers to monitor in parallel the process of efflux measurements. Above all what follows next is the focus on the chamber gas volume heat exchange process with the covered top layer 
soil surface by the chambers shell. This is based on putting forward several temperature models as functions to the soil efflux equation. Likewise the chamber gas volume temperature affects with plant photosynthesises is observed. Subsequently the research is extended to a pressure model starting with the pressure equilibrium condition between inside and outside the chamber. This is done through firstly finding the ambient pressure at the location where the chamber is deployed at. The respiration chamber internal pressure is affected by internal affects such as the used internal mixing fan likewise it is affected by thermal heat gains from the suns solar radiation. Furthermore external pressure changes come also of importance due to blowing wind affects which case soil surface wall shear stress. This is looked at closely by studying soil surface pressure according to the soil air movement theory whereby linking it to the soil layer pressure profile which lead to soil surface pressure gradients. Hence the top soil aeration process is covered in addition to carbon dioxide solubility in relation to top soil layer surface pressure. Respiration chambers characteristics from advantages to drawbacks are presented. Furthermore chamber insertion on the site locations is covered. Finally the relationship between soil $\mathrm{pH}$ and micro bacteria activity with efflux is shown by introducing a general model. The model relates carbon dioxide efflux production with the type of micro bacteria found in the soil sample as a function of population and surface area and other parameters.

\subsection{Chamber Gas Sensors, Location of Instillation and Calibration}

One of the most essential parts of the respiration chamber is the gas sensor. Selecting the appropriate gas sensor for a certain type of respiration chamber always posed a challenge to scientists and designers. Unfortunately there is no simple approach to make this selection hence designers and researchers are advised to seek assistance from sensor specialists. Each sensor has certain capabilities and limitations, thus the suitability of a gas sensor depends largely on the application in which it is to be used. Different techniques for measuring carbon dioxide 
efflux have been investigated by many researchers such as [18]. Operational mode of the chamber has an impact on the sensor selection criteria.

\subsubsection{Gas Sensors and Static Chambers}

For instance static respiration chambers rely on a static pressure environment inside the chamber that provides species diffusion conditions; hence it is a reliable mode to measure soil biological activity as shown by [41]. On the other hand some would argue that the unreliability of the static mode at some instances is due to an external disturbance in the measurement. One of the setbacks in the use of static chambers is that relying on the uniform diffusive distribution of species in the gas volume will take a long period of time to achieve. Likewise it is not guaranteed always for steady conditions to prevail. Consequently that will delay the instantaneous understanding of the soil biological activity which changes at every discrete instance of time. The rate of sensor gas sampling per second all depends on the type of sensor and what biological activity is of importance for the study. Therefore this causes a time lag in measurement time till the gas species reaches the sensor head at a predefined location in the chamber. This setback depends mainly on the design constraints of the chamber. Furthermore what sometimes affects the gas sensor as reported by [19] is the location of gas sampling intake and outtake from the chamber. The mentioned case is for a gas species analyser that is located externally. It has been stated by [20] that species concentration varies within the chamber height as well as in the radial location. Deviations in efflux measurements are governed by the flow field in the chamber likewise they depend on the diffusion properties of carbon dioxide.

\subsubsection{Gas Sensors and Dynamic Chambers}

Covering the case of dynamic chambers some researchers like [21] recommended to take gas samples from the head section of the chamber. This was achieved by increasing the chambers volume where by a small cover-box is added at the headspace. Consequently this resulted in a measurements accuracy for carbon dioxide of $100 \mathrm{ppm}$, ideally even lower. Other researchers 
[22] to prove the reliability and accuracy of the mini chamber method applied it to measure methane concentrations. Dynamic chambers use blowing fans, the purpose of using mixing fans in chambers is to create a homogenous gas mixture to instantaneously perform carbon dioxide measurements as shown by [23]. The setback of using mixing fans is that they generate turbulence during the mixing process. Consequently that cases an over measurement of the carbon dioxide efflux by an amount of $2-4 \%$ as stated by [24]. To resolve the challenge of efflux over prediction researchers have used gas sample bypass methods to draw out the sample for analysis. Therefore by using the bypass approach they found that turbulence effects can be omitted from the measurements. Hence the intense mixing that took place in the head space of the chamber was the source of error to the measurement.

\subsubsection{Gas Species Sensors}

Realistically the objectives researchers and chamber designers are trying to accomplish is to define an instrument specification that meets their minimum requirements. Generally in the scientific community infrared gas sensors have gained the confidence of researchers [25]. The main reason for that is their ability to take measurements at time durations less than a second. Additionally the following factors/observations should be considered when selecting the gas sensor:

1- The specifications should define the gases ranges of the sensors

2- Carbon dioxide is what is mainly required to be measured. Additionally what are also required to be determined are the back ground gases in the monitoring area. Usually for interest are methane and NOx which require gas chromatography.

3- The temperature ranges $\left(-10^{\circ} \mathrm{C}\right.$ to $\left.60{ }^{\circ} \mathrm{C}\right)$ inside the chamber in which the sensor is to be installed should be within the sensor specifications and should be suitable for the gases to be monitored.

4- A typical specification for humidity is $95 \%$ non-condensing. 
Is a Continuous mode of Measurement important? This kind of mode to run a respiration chamber on comes very handy when deployed on not easy to access locations. Whereby it can be left unattended and data gathering can be conducted and recorded with timed aeration periods. This was clearly shown by the results of [26] notably the point of reliability of repeated measurements is a must. Significantly what is clear from the duration of the measurements those 25 seconds that where required to reach equilibrium concentration state. The jump in concentration was about $300 \mathrm{ppm}$ then it was followed by aeration, while at other instances concentration took 15 minutes to stabilize.

In conclusion, for respiration chambers using a carbon dioxide sensor by its self is not sufficient to understand fully what is happening. Therefore in parallel of taking concentration measurements, date, time of day has to be recorded to verify the diurnal affects, temperature, inner chamber pressure and outer chamber pressure. A light intensity sensor is required in addition to a day timing recorder when measurements are taken. This means the distribution of carbon dioxide particles in the chambers should increase with temperature according to time of day. Furthermore light intensity should be recorded to verify if its cloud or sunny, while rain affects can be predicted by measuring atmospheric humidity. The optimum duration for a measurement, depends on the location of study in general, in specific it depends on the type of location characterization hence grass land, forest land, peat land, swamp, desert, etc. There is a difference in the duration time from site to site, this is attributed to several points, as an example a difference in occurring biological activity on different locations, change of response according to change of temperature. Any chamber has optimum working conditions these either depend on chamber design or in the used type of sensors. Some researchers have used an external apparatus that air conditions the chamber to keep the internal and external environmental conditions the same as seen in some of LI-COR designs. 


\subsubsection{Temperature effects on Gas Sensors}

Diurnal affects as discussed by [27] have more of an evident impact on soil efflux measurements in static chambers than dynamic ones. Gas diffusion is a function of temperature according to the kinetic gas theory as shown in equation (1.1), further more temperature varies from day time too night time. Hence carbon dioxide diffusion changes with temperature this is illustrated in equation (1.1) by the relationship of $\mathrm{v}_{\mathrm{rms}}$ velocity with temperature:

$$
\mathrm{v}_{\mathrm{rms}}=23.8(\mathrm{~T})^{0.5}
$$

Some researchers [26] have adopted a continuous approach for data sampling on the site of deployment. In particular it helps in capturing the change of measured parameters in relation to time of day and month of the year. Similarly external uncontrollable environmental disturbances occur while measurements are taken; these are attributed to seasonal affects. These affects are notably evident in the form of excess blowing winds, rain, heat wave, etc. Diurnal affects become more evident in forest site locations as found by [28] in particular the occurrence of dynamic litter, variations in wind pressure relating to tree dynamics, etc.

\subsubsection{Sensor Measurement Calibration}

No standard calibration method or means has yet been adopted by researchers to test the accuracy of soil respiration measurements [29]. The drive to find the most reliable method of calibration that wins the trust of the researcher is based on finding a method that helps the researcher get repeatable measurements on the same site. During the early stages of research in the field of efflux measurements the soda lime method was the common practice used to capture the carbon dioxide efflux. Then, with the introduction of the gas analyser method the soda lime method became less popular. A comparison between the soda lime and the infra-red gas analyser methods is covered in [30] for the reason of calibration what was reported that the soda lime method properly functioned when a $98 \%$ moisture content is provided. The author 
concluded that there was no strong correlation between both used methods on the same forest location. The soda lime method is suitable to be used to calibrate static chambers. A calibration system for soil carbon dioxide-efflux measurement chambers has been put forward by [31] for the case of open and closed dynamic chambers. This is done by firstly calibrating measurements with a previously known efflux. Another common practice used for calibrating chamber efflux measurements for chambers is the Eddy covariance (EC) method [32] the researcher is recommended to read reference [33] to further his understanding of the method. The Eddy covariance method can also be used to link the relationship between blowing wind velocity, moisture content, temperature, and Carbon dioxide concentrations [34]. The drawbacks of the Eddy covariance method is that it firstly measures the efflux coming from the ecosystem while the interest of the researchers is the amount of carbon dioxide produced by a specific soil site [35]. Secondly It only gives good results for windy conditions, therefore it will be mainly suitable to calibrate dynamic chambers [36].

A way to tackle the calibration challenge is to use soil media with predetermined water content thus soil porosity is known before the experiment. Furthermore to prepare a soil texture with known ratios of sand silt and clay this helps in knowing the soil permeability for the setup experiment. Moreover this is followed by decomposing the sources of the efflux whereby independent effluxes are used to mimic the ones generated by bacteria, plants etc. That is all according to pre agreed upon ratios of efflux contributions when the experiment is setup. This is for the purpose to create a similar example to the studied case for the measured efflux. This method was applied for a dynamic chamber case by [37] hence what affects the efflux calibration can be identified. Another secondary approach to improve the calibration method for a closed dynamic chamber is by improving the mixing rate within the chamber hence the mixing time previous to the measurement. Consequently both proved to be critical to obtain an adequate correction factor to approximate the true value of carbon dioxide soil efflux in field 
test sites [38]. One of the challenges facing calibration for both static and dynamic chambers is whether the gas source provides a steady or an unsteady efflux in time. This was stated in the study by [39] on the linear measurements of nitrogen oxide obtained by accumulating it in a closed chamber. The researcher is also recommend to read the chamber calibration steps for a closed chamber that uses commercial gas analysers type EGM-4 and LI-7000.

\subsection{Chamber Temperature Increase/Decrease and its Relation to efflux}

Discussing a general case for a soil site location on a daily basis there is heat transfer represented by total heat $\mathrm{Q}_{\text {total }}[\mathrm{W}]$ into and out of the soil mass at one location. Thus the gained heat at the site location without the cover of a chamber is $Q_{\text {Soilw }}[\mathrm{W}]$ as shown in equation (1.2):

$$
\mathrm{Q}_{\text {Soilw }}=\mathrm{Q}_{\text {total }}
$$

There are basically three different processes whereby heat can be transported into the soil mass these are: heat conduction $\mathrm{Q}_{\text {con }}[\mathrm{W}]$, heat convection $\mathrm{Q}_{\text {conv }}[\mathrm{W}]$ (with or without latent heat transport) and heat radiation $\mathrm{Q}_{\mathrm{rad}}[\mathrm{W}]$. Furthermore the summation of these terms leads to the total heat transferred to the soil mass as shown in equation (1.3):

$$
Q_{\text {total }}=Q_{\text {con }}+Q_{\text {rad }}+Q_{\text {conv }}
$$

Hence the thermal efficiency for the process of heat transfer to a soil location without chamber cover can be represented in $\eta_{\mathrm{w}}$ whereby it's the ratio of heat gained for a soil location without an installed chamber over the total heat the location (this is the considered as the ideal case):

$$
\eta_{\mathrm{w}}=\frac{\mathrm{Q}_{\text {Soilw }}}{\mathrm{Q}_{\text {total }}}
$$


Moreover considering the comparison case where heat is transferred to the soil mass when a chamber is placed on location $\mathrm{Q}_{\text {Soilwt }}[\mathrm{W}]$ this would result in a new load heat term $\mathrm{Q}_{\text {totaln }}[\mathrm{W}]$ as shown in:

$$
\mathrm{Q}_{\text {Soilwt }}=\mathrm{Q}_{\text {totaln }}
$$

The new heat term $Q_{\text {totaln }}$ is the summation of the total heat without a chamber with heat gain or loss $\Delta \mathrm{Q}[\mathrm{W}]$ as shown in:

$$
\mathrm{Q}_{\text {totaln }}=\mathrm{Q}_{\text {total }} \pm \Delta \mathrm{Q}
$$

This means that with the installation of the chamber on site location the heat load is changed. Hence a new thermal efficiency is defined $\eta_{w t}$ where it is defined as the ratio of

$$
\eta_{\mathrm{wt}}=\frac{\mathrm{Q}_{\text {Soilwt }}}{\mathrm{Q}_{\text {total }}}
$$

In conclusion to preserve the locations thermal integrity as much as possible chamber designers must aim to achieve the following assumption:

$$
\eta_{\mathrm{w}} \geq \eta_{\mathrm{wt}}
$$

Consequently this proves the reason why many commercial companies that produce respiration chambers aim to use external environmental systems [40]. That is in order to sustain the same heat balance between inside and outside the chamber. For simplicity equation (1.8) can be used, by measuring the temperature difference $\Delta \mathrm{T}$ [Kelvin] experimentally, the amount of gained heat can be calculated by difference in internal energy where $c_{v}$ is the specific heat capacity for air at constant volume:

$$
\mathrm{Q}_{\text {totaln }}=\mathrm{c}_{\mathrm{v}} \Delta \mathrm{T}
$$


To purse a more detailed analysis of the temperature effects on soil efflux several temperature models are presented in the following sections.

\section{1-6-1 The Cyclic State efflux Model Related to Soil Layer Depth}

Carbon dioxide efflux is produced from the soil and is a function of soil temperature. On a sunny day when the chamber is set up on location after several minutes of deployment heat builds up in the chamber till a certain limit. This heat in turn is then transferred to the mass of soil beneath the chamber gas volume. This process can be modelled based on the lumped analysis approach for time varying convection as shown in equation (1.9). Soil temperature $\mathrm{T}_{\text {Soil }}[\mathrm{K}]$ at a specified instance of time $\mathrm{t}[\mathrm{sec}]$. The soil heat capacity is $\mathrm{c}[\mathrm{J} / \mathrm{kg} \mathrm{K}]$ likewise the density of the soil is $\rho_{\mathrm{s}}\left[\mathrm{kg} / \mathrm{m}^{3}\right]$ this is for a studied volume of soil $\mathrm{V}\left[\mathrm{m}^{3}\right]$ located in the $\mathrm{O}$ horizon. The initial chamber temperature after closure is considered as $\mathrm{T}_{\mathrm{i}}[\mathrm{K}]$. Furthermore the average heat transfer coefficient for convection is $\overline{\mathrm{h}}\left[\mathrm{W} / \mathrm{m}^{2} \mathrm{~K}\right]$ this is considered for the soil

surface interface $A_{s i}\left[\mathrm{~m}^{2}\right]$ within the inner chamber gas volume. Additionally the asymptotic temperature of the gas volume in the chamber is $\mathrm{T}_{\infty}[\mathrm{K}]$.

$$
\mathrm{T}_{\text {Soil }}=\left(\mathrm{T}_{\mathrm{i}}-\mathrm{T}_{\infty}\right) \exp \left(-\frac{\overline{\mathrm{h}} \mathrm{A}_{\mathrm{si}}}{\rho_{\mathrm{s}} \mathrm{cV}} \mathrm{t}\right)+\mathrm{T}_{\infty}
$$

Equation (1.9) proves the point why regular ventilation is required during measurements, this is kind of approach is used in the LI-8100A chamber model as shown in Error! Reference source not found.. By substituting equation (1.9) into the Arrhenius equation results in equation (1.10) this resembles a simple form of the efflux equation. Hence the relationship between soil efflux ef $\left[\mathrm{mole} / \mathrm{m}^{2} \mathrm{~s}\right]$ and soil temperature $\mathrm{T}_{\text {Soil }}$ can be found where the constant $\mathrm{d}\left[\mathrm{mole} / \mathrm{m}^{2} \mathrm{~s}\right]$ is the pre-exponential constant $\mathrm{E}[\mathrm{kJ} /$ gmole] the activation energy and and $\mathrm{R}$ the ideal gas constant. 


$$
\text { ef }=d \cdot \exp \left(\frac{-E}{\text { RT }_{\text {Soil }}}\right)
$$

\section{1-6-2 The efflux Model Related to Heat Radiation}

Depending on the chambers role of what intended efflux is to be measured, there are transparent chambers and none transparent ones (sometimes called soil flux chambers) like the SRC1chamber model [41] as shown in Figure 1. The outer chamber shell for most of the commercial chambers (used to measure soil efflux) is taken to have a white colour.

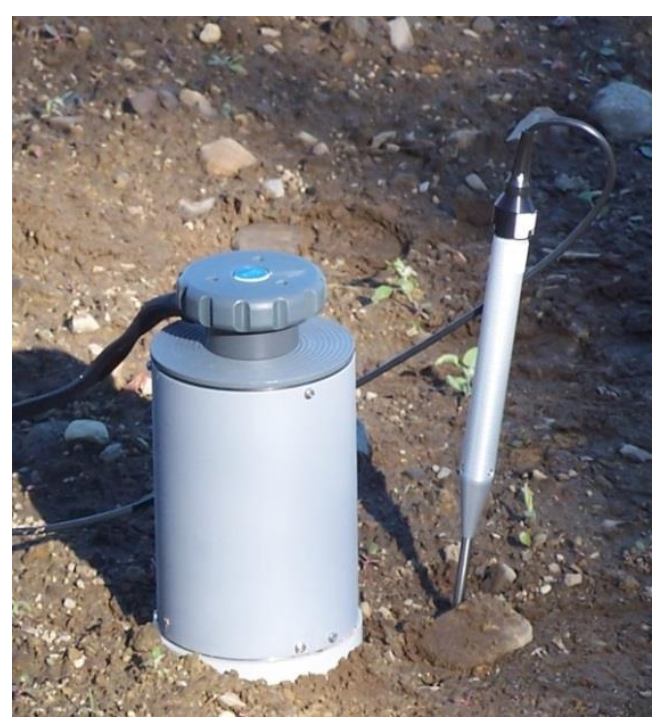

Figure 1: The PP Systems SRC-1 none transparent chamber model used to measure soil efflux.

The reason for that is with adsorption of heat a rise of internal temperature occurs. Hence an unwanted disturbance to the internal micro climate is eminent. This emitted radiation heat can be calculated using equation (1.11) where $Q_{\text {emit }}[\mathrm{w}]$ is the emitted radiation from the chamber. Emissivity is referred to as $\varepsilon$ for a white surface it takes the value of $\varepsilon=0.9$. The Stephan Boltzmann constant is $\sigma=5.67 \times 10^{-8} \mathrm{~W} / \mathrm{m}^{2} \mathrm{k}^{4}$. The outer surface shell wall surface of the chamber is $A_{w}\left[\mathrm{~m}^{2}\right]$. Likewise the chamber outer wall shell temperature is $T_{s}[k]$. 


$$
\mathrm{Q}_{\mathrm{emit}}=\sigma \varepsilon \mathrm{A}_{\mathrm{w}} \mathrm{T}_{\mathrm{s}}^{4}
$$

Transparent chambers are used to see the diurnal effects on carbon dioxide efflux measurements this is evident in commercial chamber model CPY-4 made by PP Systems. For instance chamber CPY-4 [42] is used specifically for low laying vegetation this is clearly shown in Figure 2.

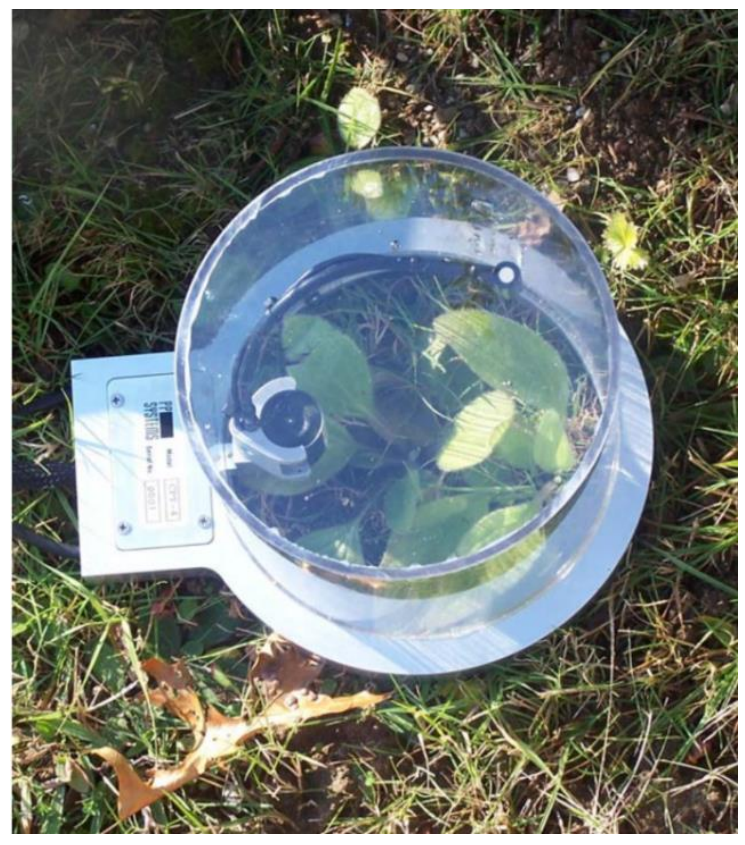

Figure 2: The CPY-4 transparent chamber used to measure efflux from low lying vegetation.

In the case of transparent chambers, researchers have noticed on a sunny day that after several minutes of chamber site deployment water condensation starts occurring on chamber walls referring to rise of internal temperature. This is called the absorbed heat $\mathrm{Q}_{\mathrm{abs}}[\mathrm{w}]$ as shown in equation (1.12). The absorptivity of the chamber transparent shell is $\alpha$ and $Q_{\text {inc }}[\mathrm{w}]$ is the rate at which radiation is incident on the surface:

$$
\mathrm{Q}_{\mathrm{abs}}=\alpha \mathrm{Q}_{\mathrm{inc}}
$$

On the contrary the reverse conditions do occur during winter where heat loss dose occur which might cause plant freeze at some instances. The radiant flux in the chamber is due to carbon 
dioxide and water vapour contained in the air. Other gases such as $\mathrm{N}_{2}$ and $\mathrm{O}_{2}$ have nonpolar, symmetrical molecular structures, thus they do not emit or absorb significant amounts of energy.

In this section a model is proposed for a transparent cylindrical chamber to show the effects of solar radiation on contained water vapour and carbon dioxide in the chambers gas volume and how it contributes in heating the chambers air gas volume. Considering that for a location after duration of time an average temperature inside the chamber becomes of $\mathrm{T}_{\text {heatedair }}=310[\mathrm{~K}]$ whereby the emissivity doesn't change. Meanwhile for the case of a chamber located at a fixed site the total atmospheric pressure is considered to be $P_{t}=1$ [atm]. Then the water vapour partial pressure is $\mathrm{P}_{\mathrm{w}}=0.02$ [atm] this is based on making the assumption that the atmospheric water average volume fraction is $2 \%$. Moreover to find the emissivity values for water vapour inside the chamber that has a diameter of $\mathrm{D}=0.5[\mathrm{~m}]$ is based on knowing the value of $\mathrm{T}_{\text {heatedair }}$ and by calculating $\mathrm{P}_{\mathrm{w}} \mathrm{D}$ which turns out to be $0.01 \mathrm{~m}$. atm .Hence by using Figure 3 this leads to a value of emissivity of $\left(\epsilon_{\mathrm{w}}\right)_{1}=0.14$.

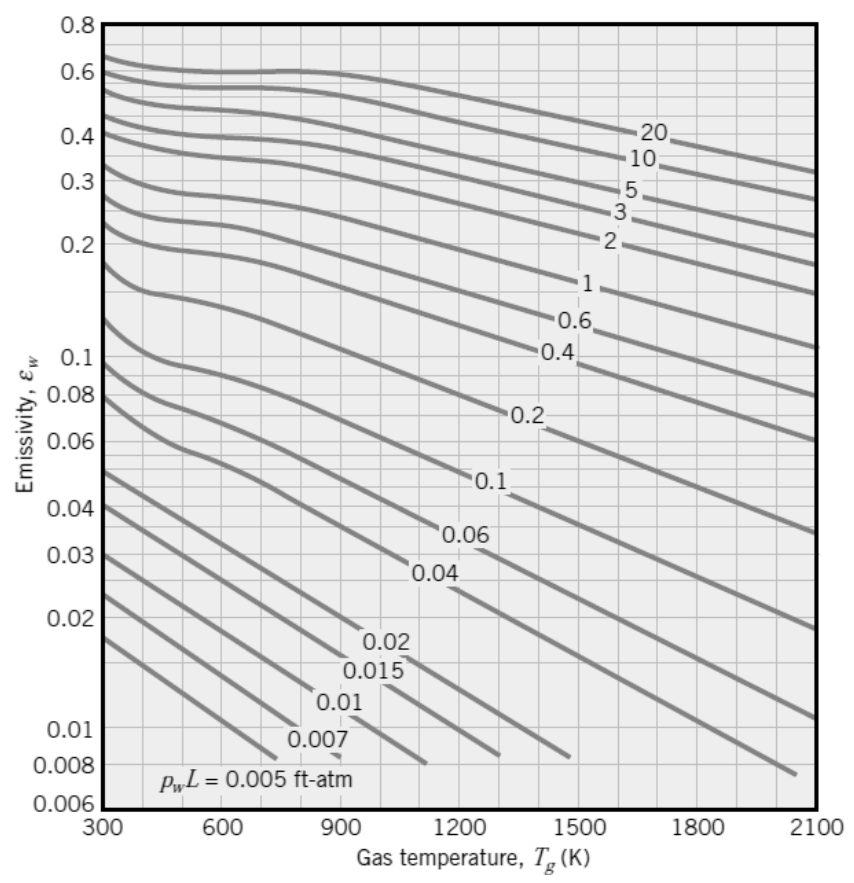


Figure 3: Emissivity of water vapour in a mixture with none radiating gases at 1-atm total

$$
\text { pressure [36]. }
$$

Like wise to find the correction factor of water vapour is by using Figure 4 where the average pressure is $0.5\left(\mathrm{P}_{\mathrm{w}}+\mathrm{P}_{\mathrm{t}}\right)=0.505 \mathrm{~atm}$ moreover we know that $\mathrm{P}_{\mathrm{w}} \mathrm{D}=0.01 \mathrm{~m}$. atm consequently the correction factor is taken to be $c_{p w}=1$ hence the actual gas emissivity from water vapour is $\left(\epsilon_{\mathrm{w}}\right)_{\text {actual }}=0.14$. As with the Stephane Boltzmann constant it is $\sigma=5.67 \times$ $10^{-8}\left[\mathrm{~W} / \mathrm{m}^{2} \mathrm{k}^{4}\right]$

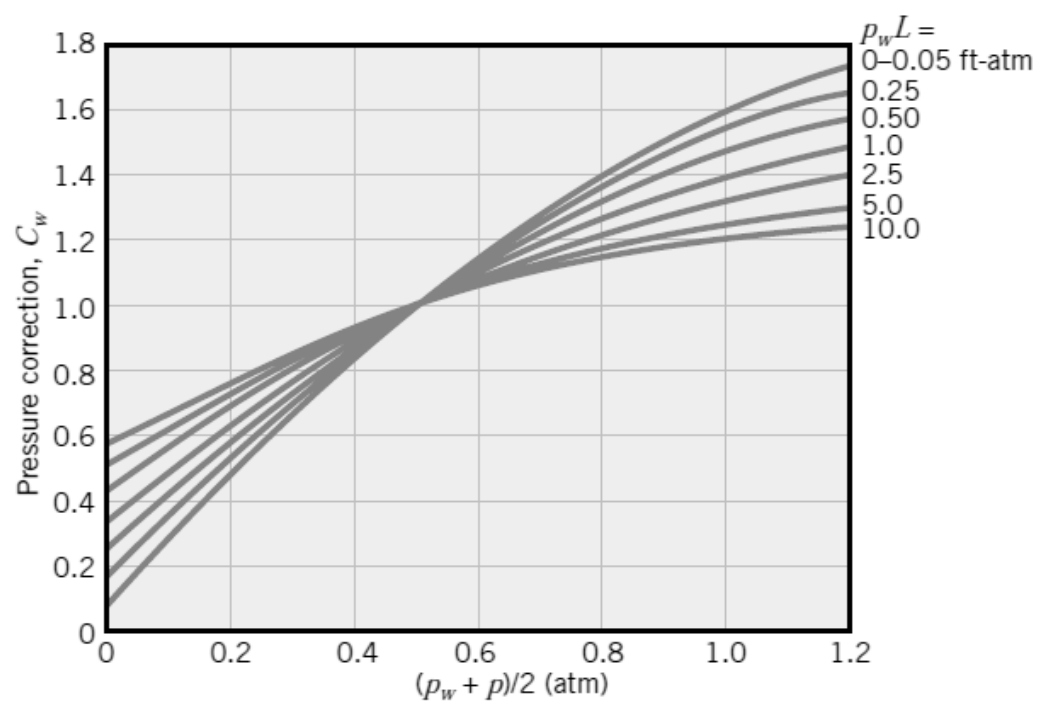

Figure 4: Correction factor for obtaining water vapour emissivities at pressures other than 1 atm [43].

The total rate of heat transfer per unit of length $\mathrm{L}_{\mathrm{h}}[\mathrm{m}]$ for the chamber heated air $\mathrm{T}_{\text {heatedair }}$ to the chamber wall if the wall emissivity is unity and its temperature is $\mathrm{T}_{\text {ChmaberWall }}$ :

$$
\frac{\mathrm{q}_{\mathrm{w}-\mathrm{c}}}{\mathrm{L}_{\mathrm{h}}}=\pi \mathrm{D}\left(\epsilon_{\mathrm{w}}\right)_{\text {actual }} \sigma\left(\mathrm{T}_{\text {heatedair }}^{4}-\mathrm{T}_{\text {ChamberWall }}^{4}\right)
$$

On the other hand studying gas emissivity for carbon dioxide is based also on considering that the total atmospheric pressure is $\mathrm{P}_{\mathrm{t}}=1$ [atm] . Moreover carbon dioxide partial pressure is 
taken to be $\mathrm{P}_{\mathrm{c}}=4 \times 10^{-4}$ [atm] based on that the location has an atmospheric concentration of carbon dioxide of $400 \mathrm{ppm}$. Furthermore the chamber has a diameter of $\mathrm{D}=0.5 \mathrm{~m}$ meaning that $P_{c} D=2 \times 10^{-4}\left[\mathrm{~m}\right.$. atm]. Hence by knowing $\mathrm{P}_{c} \mathrm{D}$ and $\mathrm{T}_{\text {heatedair }}$ and using Figure 5 the emissivity for carbon dioxide has an emissivity value of $\left(\epsilon_{\mathrm{c}}\right)_{1}=0.006$. However by using Figure 6 and knowing that total pressure is $1[\mathrm{~atm}]$ and $\mathrm{P}_{\mathrm{c}} \mathrm{D}$ leads to the emissivity correction factor for carbon dioxide to be $c_{\mathrm{pc}}=1$. Consequently the actual emissivity for carbon dioxide is $\left(\epsilon_{\mathrm{c}}\right)_{\text {actual }}=0.006$ whereby it is applied to equation (1.14). Thus this gives the radiative heat transfer per linear $L_{h}[m]$ from the carbon dioxide to the chamber wall if the wall emissivity is unity and its temperature is $\mathrm{T}_{\text {ChamberWall }}$ :

$$
\frac{\mathrm{q}_{\mathrm{c}-\mathrm{c}}}{\mathrm{L}_{\mathrm{h}}}=\pi \mathrm{D}\left(\epsilon_{\mathrm{c}}\right)_{\text {actual }} \sigma\left(\mathrm{T}_{\text {heatedair }}^{4}-\mathrm{T}_{\text {ChamberWall }}^{4}\right)
$$

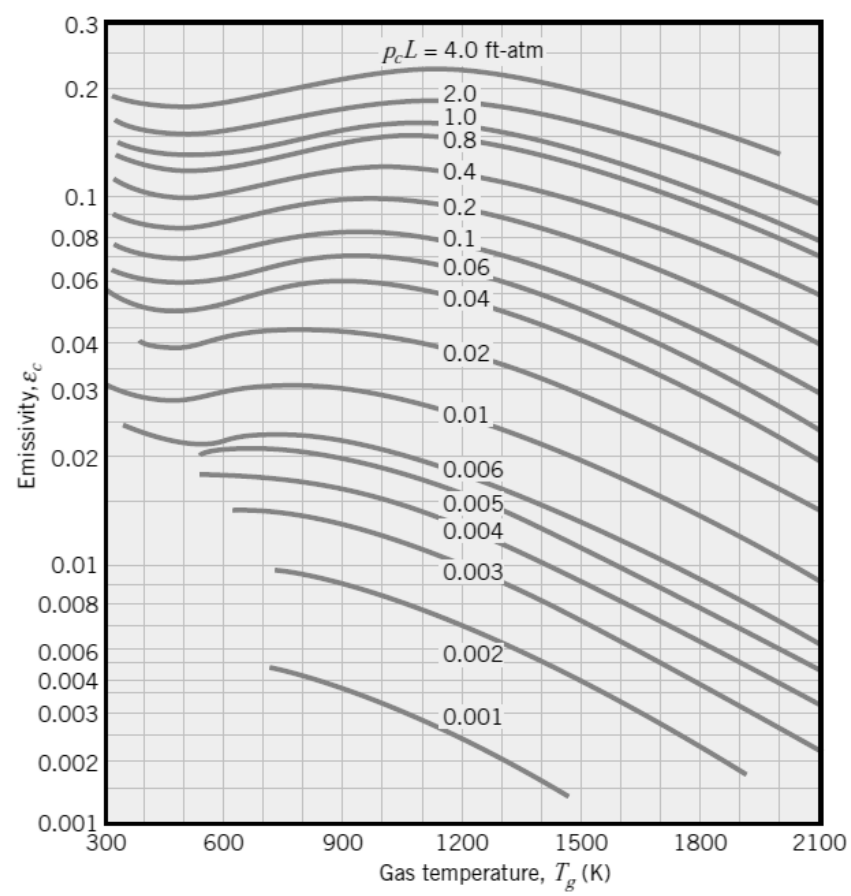

Figure 5: Emissivity of carbon dioxide in a mixture with none radiating gases at 1-atm total pressure [43]. 


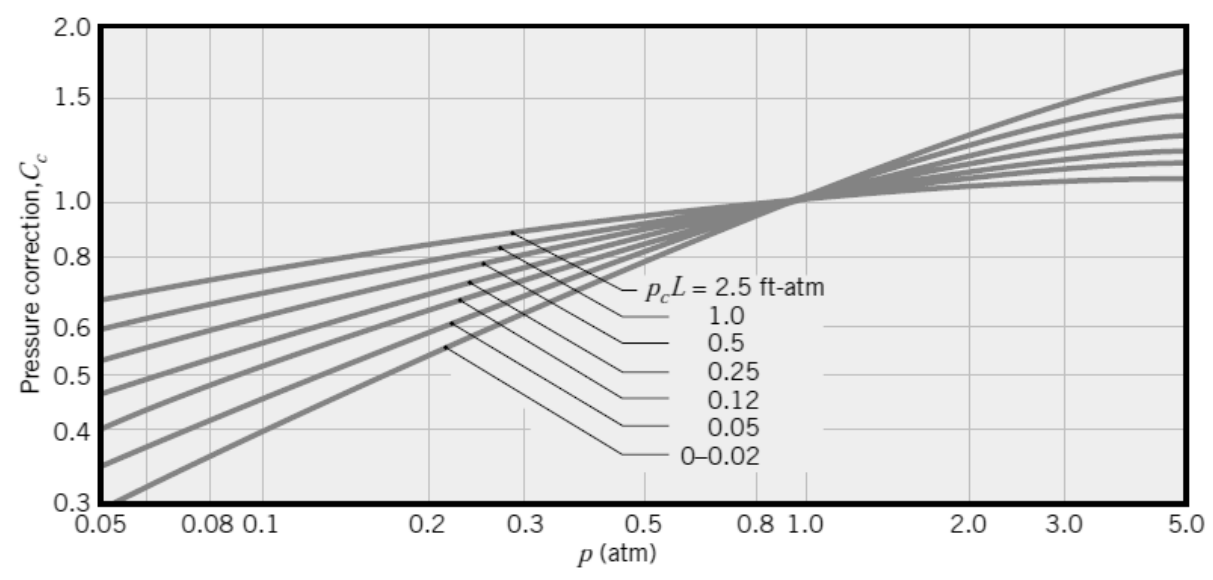

Figure 6: Correction factor for obtaining carbon dioxide emissivities at pressures other than $1 \mathrm{~atm}[43]$.

Lastly the total radiant flux from the contained carbon dioxide and water vapour in the chamber to the heated air inside the chamber is:

$$
\frac{\mathrm{q}_{\text {total }}}{\mathrm{L}_{\mathrm{h}}}=\pi \mathrm{D}\left(\epsilon_{\mathrm{c}}+\epsilon_{\mathrm{w}}\right) \sigma\left(\mathrm{T}_{\text {heatedair }}^{4}-\mathrm{T}_{\text {ChmaberWall }}^{4}\right)
$$

A numerical model based on heat balances was developed by [44] for a soil mulch atmosphere case using the finite difference scheme, where latent heat content and radiative among others were considered. Such a model can give hints to the potential of applying such models in available CFD packages. Rise of chamber inner temperature is attributed to carbon dioxide concentration rise in the chamber due to the high heat capacity of carbon dioxide. For measurements lasting in the range of several minutes to an hour it is assumed that the soil temperature has the same temperature as the ambient air. Hence, the studied case is steady state one.

\section{1-6-2 The Daily Cyclic State efflux Model Related to Soil Layer Depth}

The thermal properties of the soil are strongly dependent on soil porosity [45]. The soil temperature which is achieved through the solar radiation projected during the day on the 
studied soil area reflects on the temperature of the water moisture content, raising the temperature of the soil will increase the evaporation pressure. Soil temperature cyclic behaviour can be modelled using equation (1.16) as shown in detail by [46], where $\mathrm{T}_{\mathrm{zt}}$ is a function of time and depth, $\mathrm{T}_{\mathrm{a}}$ is the average soil temperature, $\mathrm{t}$ is time. Heat conduction is governed by the thermal properties of the soil composition; volumetric heat capacity and heat conductivity are represented in the $\mathrm{k}_{\mathrm{c}}$ constant. The frequency of the cyclic behaviour is represented by $w=2 \pi / \tau_{p}$ where $\tau_{p}$ is the period of cycle which can be day or year. Likewise the term $\sigma_{\mathrm{t}}$ represents $\mathrm{w} / 2 \mathrm{k}\left[\mathrm{m}^{-2}\right]$ as seen in the following:

$$
\mathrm{T}_{\mathrm{zt}}=\mathrm{T}_{\mathrm{a}}+\mathrm{A}_{0} \mathrm{e}^{-\left(\sigma_{\mathrm{t}}\right)^{0.5} \mathrm{z}} \sin \left(\mathrm{wt}-\left(\sigma_{\mathrm{t}}\right)^{0.5} \mathrm{z}\right)
$$

Cyclic temperature change during the day and night cases a change of the mass diffusion coefficient, affecting the carbon dioxide efflux produced mainly at the top surface soil layer near the surface. The temperature cycle simple model is covered in many soil physics books, as an example in [46]. The temperature damping model that considers thermos physical properties of the soil is covered in [45], other interesting approaches are also available in [47]. The power of equation (1.17) it can be applied for the top surface layer of soil on both the bacteria and plant roots for a certain depth and time of the day.

$$
\text { ef }=d \cdot \exp \left(\frac{-\mathrm{E}}{\mathrm{RT}_{\mathrm{zt}}}\right)
$$

The following research paper [48] has also proposed a similar approach to predict temperature variations in relation to time and soil depth for geothermal heat exchanger applications.

\section{1-6-3 The Steady state efflux Model Related to Soil Layer Depth}

Researchers in [49] have pointed to temperature variations in the soil as a cause of this underestimation of flux, where the biological response factor differs from one location to 
another. That is because they assume a uniform temperature distribution in the studied soil layer while in real life it is not the case. Usually a uniform temperature is modelled using equation (1.18). The soil temperature at the surface interface with the atmosphere is $\mathrm{T}_{\mathrm{ss}}[\mathrm{k}]$. The soil temperature at the bottom of the top layer is $\mathrm{T}_{\mathrm{bl}}[\mathrm{k}]$. The layer soil thermal conductivity is $\mathrm{k}_{\mathrm{c}}\left[\mathrm{w} / \mathrm{m}^{2} \mathrm{k}\right]$. The heat source or sink term $\mathrm{q}[\mathrm{w}]$ can either represent heat gained during the day can be regarded or heat loss term during the night. $\mathrm{L}[\mathrm{m}]$ is the total thickness of the soil layer.

$$
\mathrm{T}_{\mathrm{ins}}=\left(\frac{\mathrm{T}_{\mathrm{bl}}-\mathrm{T}_{\mathrm{ss}}}{\mathrm{L}}+\frac{\mathrm{q}}{2 \mathrm{k}_{\mathrm{c}}}(\mathrm{L}-\mathrm{z})\right) \mathrm{z}+\mathrm{T}_{\mathrm{ss}}
$$

Hence by substituting equation (1.18) into the Arrhenius equation leads to equation (1.19) which is a steady state equation relating to the thermal qualities and thickness of the soil slayer.

$$
\text { ef }=\text { d. } \exp \left(\frac{-E}{\mathrm{RT}_{\text {ins }}}\right)
$$

Some researchers have proposed [50] in order to improve efflux measurements is through considering the atmospheric ambient air temperature on the site of study as the contributing factor that affects biological activity. Consequently this adopted assumption by the research community is wrong because soil air temperature is a function of the lumped heat capacitance of the soil layer; hence the growth dynamics of bacteria will also be affected hence the efflux will be affected.

$$
\mathrm{T}_{\mathrm{ins}} \neq \mathrm{T}_{a}
$$


Furthermore other authors [51] have noted that soil wetness affects the total thermal resistance of the soil at the location of study through the use of air-earth heat exchangers.

\section{1-6-4 The Steady state efflux Model Related to Soil Layer Depth}

Soil efflux is governed by soil temperature as shown by [52] which also found there is no optimum soil temperature for biological activity and that after a certain temperature rise biological activity is halted. The paper summarises several experimental extrapolated models relating to temperature and soil efflux. Likewise other researchers [53] have shown that soils that have high porosity values responded with less sensitivity to temperature changes. Furthermore what also affects carbon dioxide efflux is the soil microbial community behaviour where they adapt to cold conditions therefore they exhibit a stronger temperature response when compared to the ones that exist in warmer climates. Some have argued that soil porosity is the contributor for wrong efflux measurements, where low porosity caused underestimation while high porosity caused over estimation [54]. Other researchers [55] have stated that temperature and porosity are the two major factors affecting efflux. The discussed point can be proved by using the Sutherland equation [56]. The Sutherland equation for carbon dioxide is (1.21), it represents the dynamic viscosity of the gas at two instances, one is the reference state and the second is at the temperature of concern. The carbon dioxide constants are taken as follows $C=240[\mathrm{~K}]$ while the reference dynamic viscosity for carbon dioxide is $\mu_{\left(\mathrm{CO}_{2}\right)_{0}}=$ $14.8[\mu \mathrm{Pa} . \mathrm{s}]$ in relation to the reference temperature $\mathrm{T}_{0}=293.15[\mathrm{~K}]$ :

$$
\mu_{\mathrm{CO}_{2}}=\mu_{\left(\mathrm{CO}_{2}\right)_{0}} \frac{\mathrm{T}_{0}+\mathrm{C}}{\mathrm{T}+\mathrm{C}}\left(\frac{\mathrm{T}}{\mathrm{T}_{0}}\right)^{1.5}
$$

By applying equation (1.21) into the Darcy equation this leads to the efflux form of the equation as a function of temperature: 


$$
\text { ef }=-\frac{-\mathrm{k} \cdot \rho_{\mathrm{CO}_{2}}}{\mathrm{MW}_{\mathrm{CO}_{2}} \cdot \mu_{\left(\mathrm{CO}_{2}\right)_{0}}} \frac{\mathrm{T}+\mathrm{C}}{\mathrm{T}_{0}+\mathrm{C}}\left(\frac{\mathrm{T}_{0}}{\mathrm{~T}}\right)^{1.5} \frac{\left(\left[\mathrm{CO}_{2}\right]_{\mathrm{S}} \cdot \mathrm{P}_{\mathrm{TS}}-\left[\mathrm{CO}_{2}\right]_{\mathrm{B}} \cdot \mathrm{P}_{\mathrm{TB}}\right)}{\mathrm{L}}
$$

Several researchers have demonstrated that during a drought an occurrence of a strong dependency of carbon dioxide efflux and isotopic compensation that effects soil water content [57]. Conversely the author of [58] sees that a better understanding of the efflux in a forest site location is based on predicting its carbon pool. Likewise [59] argued that GPP (gross primary production) does not have an effect on efflux production in the forest ecosystems. Forest soil efflux measurements (that contained considerable sand levels in its texture) taken at different seasons of the year were presented by [60] they used both the EC and chamber methods, the presented data showed the relationship of soil respiration with temperature. The researchers in this paper mentioned that a relationship between carbon dioxide and friction velocity was found. They also claimed that they have derived a model with the required constants to use for grassland respiration and other sites.

There is a location efflux relationship with seasonal variance done by [61] done through using the EC method. This was followed by [62] more specifically for a forest site they also which also focused on time of the year and temperature effects on soil respiration efflux. Attention has been drawn in [62] to diurnal measurements taken over a two year period have shown that climate changes relating to temperature increase the carbon efflux. One of the setbacks stated by researchers [63] in relation to closed systems is that they underestimate the soil efflux by about $15 \%$, which was observed through the collected experimental data.

\section{1-6-5 Chamber Temperature effects on Plant Photosynthesis and Cellular Respiration}

The temperature affects almost all aspects of the respiration processes. These include biological processes, such as germination of seeds, plant growth, root development and activity, microbial activity, etc. The relationship between the temperature and the biochemical processes of the 
respiration is usually described by an exponential equation called the Arrhenius equation, as in the following:

$$
w_{i}=d_{p e} e^{\frac{-E_{i}}{R T}}
$$

Where $d_{p e}$ is a pre-exponential constant, $E_{i}$ is the activation energy, $R$ is the universal gas constant, and $\mathrm{T}$ is the temperature. Photosynthesis is a process used by plants and other organisms to capture the energy of the sun in order to split off the water's hydrogen from oxygen. It is estimated that about $40 \%$ of the soil respiration is from plant roots [64]. While hydrogen is combined with carbon dioxide (absorbed from air or water) to form glucose and to release oxygen, photosynthesis is just the opposite of cellular respiration. The chemical equation (1.24) of photosynthesis is $6 \mathrm{CO}_{2}$ (carbon dioxide) and $6 \mathrm{H}_{2} \mathrm{O}$ (water) and that makes $6 \mathrm{O}_{2}$ (oxygen) and $\mathrm{C}_{6} \mathrm{H}_{12} \mathrm{O}_{6}$ (glucose), or

$$
\underset{\text { Carbon Dioxide }}{6 \mathrm{CO}_{2}}+\underset{\text { Water }}{6 \mathrm{H}_{2} \mathrm{O}} \stackrel{\text { Light }}{\longrightarrow} \mathrm{C}_{6} \mathrm{H}_{12} \mathrm{O}_{6}+\underset{\text { Glucose }}{6 \mathrm{O}_{2}}
$$

What is missing in the chemical equation (1.24) is the capture of energy from sunlight. However, the two processes take place through a different sequence of chemical reactions and in different cellular compartments. Cellular respiration in living cells, in turn, use the fuels derived from glucose and oxidize the hydrogen and carbon to release the energy of the sun and to re-form water and carbon dioxide, as expressed in the following formula (1.25)

$$
\underset{\text { Glucose }}{\mathrm{C}_{6} \mathrm{H}_{12} \mathrm{O}_{6}}+\underset{\text { Oxygen }}{6 \mathrm{O}_{2}} \rightarrow \underset{\text { Carbon Dioxide }}{6 \mathrm{CO}_{2}}+\underset{\text { Water }}{6 \mathrm{H}_{2} \mathrm{O}}
$$

Cellular respiration is a combustion reaction. That does not clearly resemble a combustion reaction when it occurs in a living cell. This difference is due to the fact that it occurs in many separate steps. While the overall reaction is combustion, no single reaction that comprises it is a combustion reaction. Plant respiration is limited by the process of diffusion. Plants take in carbon dioxide through holes on the undersides of their leaves known as stoma or pores. 


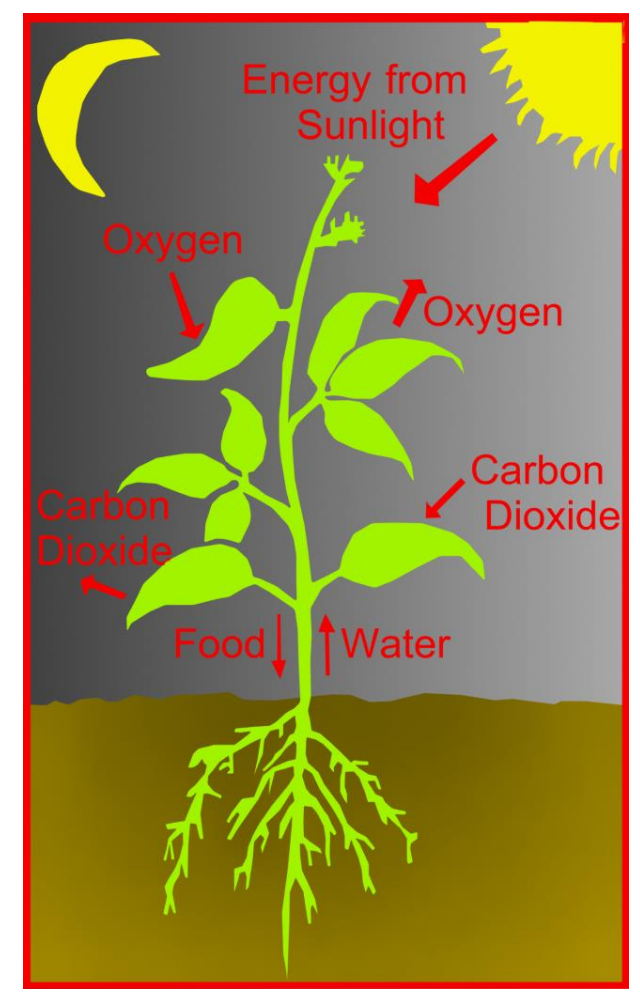

Figure 7: An illustration showing plant activity during the day which is called Photosynthesis (shown on the right hand side) and the night activity which is called Cellular Respiration (shown on the Left hand side).

However, most plants require little air. They have relatively few living cells outside their surface because the air (which is required for metabolic content) can penetrate only skin deep. Nevertheless, most plants are not involved in highly aerobic activities, and thus have no need for these living cells. This explains why there are several sources of carbon dioxide. Having plants in the chamber is one of these sources, while the other source is the bacteria of the soil. This occurs during the day activity, while during the night plants perform the role of a carbon dioxide source sink. For more details on the process of photosynthesis, see [65]. When the soil is covered by vegetation, water can then be transported from anywhere in the root zone, via the roots, stems and leaves into the atmosphere; the so-called soil-plant-atmosphere-continuum (SPAC). The loss of water from soil via plants is called transpiration. Transpiration is mostly a passive process. While the leaf stomata are open for the exchange of carbon dioxide and 
oxygen for the process of photosynthesis, water vapour is lost to the atmosphere. The deficit is replenished by water uptake by the roots. The driving force for the transpiration stream is the large potential difference between the water in the soil and the water in the atmosphere. Again the deficit is replenished by the water uptake by the roots. When the winds blow, a thin boundary layer occurs in different regions of the plant and the transport of water vapour from the leaves into the atmosphere is turbulent. In this case, the stomata will close when the roots cannot take up enough water to satisfy the evaporative demand. Then, with the transpiration, photosynthesis is also interrupted, which will result in yield reductions. Under a full vegetation cover, evaporation from the soil can, generally, be neglected. When there is no breeze, the air surrounding a leaf becomes increasingly humid thus reducing the rate of transpiration. When a breeze is present, the humid air is carried away and replaced by the drier air. When the soil is partially covered with vegetation, water is lost by both evaporation and transpiration, which are usually lumped together as evapotranspiration.

The wind speed affects the porosity of the soil due to the increased soil liquid uptake by the plant roots through the wind action on the plant causing more water to be ejected by the plant stems into the chamber entrainment. The type of vegetation that controls the soil processes involving the carbon dioxide fluxes, accumulation, and transport in a chaparral ecosystem is discussed in [66].

\subsection{Pressure effects on efflux Measurement Chambers}

Effects of external/internal pressure fluctuations on chamber measurements have been observed. Such fluctuations were found to this lead to over and underestimation of efflux measurements. The authors in [67] corroborated past work by demonstrating the importance of heterogeneous pressure fields in promoting gas movement in porous soils. They further suggested that fluctuations in the static pressure fields introduced by wind interactions with terrain and vegetation may lead to pressure pumping effects at the soil surface, hence a large 
spatial inhomogeneity in soil fluxes of trace gases occurs. Weather patterns play an important role as stated by [68] in carbon dioxide efflux production for a grassland location. When there is no wind for instance, storage of carbon dioxide in the soil occurs. This carbon dioxide studied for the site is flushed out when the soil surface is subjected to high winds during the day time, while during the night time carbon dioxide accumulates in the soil.

\subsubsection{Chamber Ambient Pressure}

Once the researcher can identify at what elevation the site is at, he can calculate the atmospheric pressure according to this relation (1.26). The atmospheric pressure $\mathrm{P}_{\mathrm{atm}}[\mathrm{Pa}]$ is related to location elevation $\mathrm{z}[\mathrm{m}]$ in relation to sea-level. The standard pressure at sea level is $\mathrm{P}_{\mathrm{o}}=$ $101325[\mathrm{~Pa}]$. Earths gravitational acceleration is $\mathrm{g}=9.8\left[\mathrm{~m} / \mathrm{s}^{2}\right]$. The molar mass of dry air is $\mathrm{M}=29$ [g/mole]. The sea level standard temperature is $\mathrm{T}_{\mathrm{o}}=288.15[\mathrm{~K}]$. The universal gas constant $\mathrm{R}=8.314[\mathrm{~J} /$ mole. Kelvin]:

$$
\mathrm{P}_{\mathrm{atm}}=\mathrm{P}_{\mathrm{o}} \exp \left(-\frac{\mathrm{M}}{\mathrm{RT}_{\mathrm{o}}} \mathrm{gz}\right)
$$

The number one rule in using chambers is to ensure pressure equilibrium between the inside chamber pressure $\mathrm{P}_{\text {in }}[\mathrm{Pa}]$ and the outside the atmospheric pressure $\mathrm{P}_{\text {out }}[\mathrm{Pa}]$ as shown in equation (1.27) :

$$
\mathrm{P}_{\text {in }}=\mathrm{P}_{\text {out }}
$$

In the case of closed dynamic chambers, some researchers $[69,70]$ have identified that chamber over pressurization or under pressurization causes efflux under estimation or over estimation respectively. Unfortunately the case of pressure equilibrium equation (1.27) rarely occurs. The real scenario is represented in equation (1.28) which is an upgrade for equation (1.27). It represents the relative pressure values (that's why the atmosphere pressure term is evident on 
both sides of the equation) with addition or subtraction or internal $\Delta \mathrm{P}_{\mathrm{in} \mathrm{n}}[\mathrm{Pa}]$ and external pressure $\Delta \mathrm{P}_{\text {out n }}[\mathrm{Pa}]$ represented in a summation form:

$$
\mathrm{P}_{\text {atm }} \pm \sum_{1}^{n} \Delta \mathrm{P}_{\text {in n }}=\mathrm{P}_{\text {atm }} \pm \sum_{1}^{n} \Delta \mathrm{P}_{\text {out } \mathrm{n}}
$$

\subsubsection{Chamber Internal Pressure}

Rise of internal chamber pressure can be calculated by equation (1.29) for the case of temperature rise, this is by applying the Gay Lussac law to calculate the increase in pressure relating to inner chamber temperature at start of the measurement process $\mathrm{T}_{1}$ [Kelvin] and at the end of the measurement process $\mathrm{T}_{2}$ [Kelvin], where the initial chamber pressure $\mathrm{P}_{1}[\mathrm{~Pa}]$ and the final chamber pressure is $\mathrm{P}_{2}[\mathrm{~Pa}]$ :

$$
\Delta \mathrm{P}_{\text {in } 1}=\mathrm{P}_{2}-\mathrm{P}_{1}=\mathrm{P}_{1} \frac{\mathrm{T}_{2}}{\mathrm{~T}_{1}}-\mathrm{P}_{1}
$$

While for a blowing fans, the rise of internal pressure can be calculated from equation (1.30). Fan blowing effects can be derived using the conservation of linear momentum law for control volumes. It can be derived for the nearest wall that the fan jet hits or it regarded the flow velocity ends to zero in a control volume. Then based on regarding the pressure is acting homogenously on all chamber surfaces, where fan blowing area is $A_{F a n}\left[m^{2}\right]$. The inner chamber surface area in contact with air including the covered soil surface is $A_{\text {inner }}\left[\mathrm{m}^{2}\right]$. Air density is $\rho\left[\mathrm{kg} / \mathrm{m}^{3}\right]$ and volumetric flow rate of a blowing fan is $\mathrm{Q}_{F a n}\left[\mathrm{~m}^{3} / \mathrm{s}\right]$ :

$$
\Delta \mathrm{P}_{\text {in } 2}=\frac{A_{\text {inner }}}{A_{\text {Fan }}} \rho Q_{\text {Fan }}^{2}
$$




\subsubsection{Chamber External Pressure}

Experiments conducted on the soil surface and inside the soil volume [67] have shown that pressure fluctuations over the soil surface cause an inflow or an outflow flux of species from the porous media. Some researchers [32] and [71] have found by using the EC method and chamber methods that pressure fluctuations and turbulence effects cause under-estimation or over-estimation of carbon dioxide efflux. External pressure perturbations occurring near the soil surface $\Delta \mathrm{P}_{\text {out_1 }}$ can be taken by the Reynolds decomposition as shown in equation (1.31), where $\mathrm{P}_{\mathrm{av}}[\mathrm{Pa}]$ is average pressure component and $\mathrm{P}_{\mathrm{fc}}[\mathrm{Pa}]$ is the instantaneous fluctuating pressure component:

$$
\Delta \mathrm{P}_{\text {out } \_1}=\mathrm{P}_{\mathrm{av}}+\mathrm{P}_{\mathrm{fc}}
$$

Other more advanced statistical models can be used instead of equation (1.29). Experiments in [72] have shown that external pressure disturbances in the range of [mbars] cases changes in the carbon dioxide flux in $\left[\mu \mathrm{g} / \mathrm{cm}^{2} \mathrm{~s}\right]$. This proves from the units the sensitivity of the system response to small changes. The other affect is with increase of internal pressure in the chamber that would lead to an increase in carbon dioxide partial pressure, enhancing the diffusion rate of carbon dioxide through the leaf stomata [73].

\subsubsection{Chamber Internal Condensation Pressure}

It has been noted that water vapour absorbers carbon dioxide hence lowers the carbon dioxide concentration in respiration chambers [74]. By using the Antoine equation (1.32) where vapour pressure $\mathrm{P}_{\mathrm{v}}\left[\mathrm{Pa}\right.$ and chamber temperature $\mathrm{T}_{\mathrm{c}}$ [Kelvin]. The researcher can find/predict condensation pressure in the used chamber. Water when condenses affects the gas sensors probe therefore a correction factor is used. 


$$
\mathrm{P}_{\mathrm{v}}=133.3 \exp \left(20-\frac{5132}{\mathrm{~T}_{\mathrm{c}}}\right)
$$

Hence the condensation pressure condition is when the chamber wall temperature is $\mathrm{T}_{\mathrm{c}}$ :

$$
\sum_{1}^{n} \Delta \mathrm{P}_{\text {in } \mathrm{n}} \geq \mathrm{P}_{\mathrm{v}}
$$

In conclusion temperature drop or rise should not occur abruptly inside the chamber. Hence temperature equilibrium between inside and outside the chamber when change dose occur should be slow to overcome the problem of water condensation to occur on the gas tip sensor.

\subsubsection{Soil Surface Interface Pressure and Pressure Profile}

Researchers using closed dynamic chamber on a forest site location [75] found that efflux measurements are governed by static pressure fluctuations, soil temperature and forest litter. What was also evident by [76] that an increase in pressure above the ambient pressure in closed dynamic chambers resulted in a decrease of carbon dioxide efflux measurements. It is noted in reference [77] that pressure fluctuation frequencies over the soil surface range from $10^{-4} \mathrm{HZ}$ to $10^{2} \mathrm{HZ}$. Pressure fluctuations with frequencies $<2 \mathrm{~Hz}$ have greater penetrable effect on the top soil surface [78] to depths of several centimetres with little attenuation. The theory of soil air movement was introduced by [79] it covers all the necessary aspects to model the mass transport according at the soil interface with the atmosphere. The soil surface pressure field can be describe mathematically by equation (1.34) whereby time is $\mathrm{t}[\mathrm{s}]$ furthermore the scaled period is taken as $T_{n}[s]$. The wave length of $m$ th wave in the $X$-direction is $X_{m}[\mathrm{~cm}]$ similarly $\mathrm{Y}_{\mathrm{m}}[\mathrm{m}]$ is the wave length of $\mathrm{mth}$ wave in the $\mathrm{Y}$-direction. The distance downwind is represented by $\mathrm{x}[\mathrm{cm}]$ while $\mathrm{y}[\mathrm{cm}]$ is the crosswind distance. The phase angle of $\mathrm{mth}$ wave in the $\mathrm{x}$-direction is $\phi_{\mathrm{xm}}$ [radians] likewise the phase angle of $m$ th wave in the $\mathrm{y}$-direction is 
$\phi_{\text {ym }}[$ radians]. The amplitude of the pressure wave with nth period and mth wave length is $\mathrm{a}_{\mathrm{mn}}[\mu \mathrm{ba}]$ :

$$
\begin{aligned}
P=\sum_{n=1}^{N} \sum_{m=1}^{M}\left[\frac{a_{n m}}{2} \cos \left(\frac{2 \pi t}{T_{n}}-\frac{2 \pi x}{X_{m}}-\phi_{x m}-\frac{2 \pi y}{Y_{m}}-\phi_{y m}\right)\right. \\
\left.+\frac{a_{n m}}{2} \cos \left(\frac{2 \pi t}{T_{n}}-\frac{2 \pi x}{X_{m}}-\phi_{x m}+\frac{2 \pi y}{Y_{m}}+\phi_{y m}\right)\right]
\end{aligned}
$$

In conclusion the rate of aeration can be predicted based on the power of the penetration frequency of the pressure fluctuations. What could further enhance diffusional fluxes significantly more than ground level turbulent pressure fluctuations is the Quasi-stationary pressure fields induced by wind blowing over rough topography [80]. Research by [31] has put forward that turbulence occurring in the chamber gas volume affects the boundary layer occurring over the soil surface. Consequently this causes an increase in the efflux of carbon dioxide from the soil top layer. Above all the turbulence intensity should not cause substantial flow fluxes to occur from inside to the outside of the chamber.

The soil pressure profile is covered in [81] in particular the authors shows the cyclic pressure behaviour in relation to soil depth starting from the soil surface as shown for the case of several depths. Furthermore the author of [82] studying the thermal properties of several soil samples found a relationship between soil moisture and the cyclic pressure behaviour taking into account a depth of $0.8[\mathrm{~m}]$. By knowing the concentrations of species and by measuring the total pressure between two points, species partial pressure profile can be found using equation (1.35). The root development activity is limited at the topsoil because the carbon dioxide concentration in the gas phase of a soil generally increases with depth. Scientists have linked the carbon dioxide efflux to soil physical pressure parameters such as [83]. Using the equations of Fick's law, ideal gas and continuity for carbon dioxide at a steady state, the partial pressure 
distribution for carbon dioxide $\mathrm{P}_{\mathrm{CO}_{2}}[\mathrm{kPa}]$ in the soil (valid to a depth of $\mathrm{z}_{0}=0.7[\mathrm{~m}]$ ) can be found using the derived equation (1.35):

$$
\mathrm{P}_{\mathrm{CO}_{2}}=-\alpha_{\mathrm{CO}_{2}} \frac{\mathrm{RT} \tau}{2 \mathrm{D}_{\mathrm{CO}_{2}} \in \delta \mathrm{M}_{\mathrm{CO}_{2}}}\left(\mathrm{z}^{2}-\mathrm{z}_{0}^{2}\right)+\mathrm{P}_{\mathrm{CO}_{2} \mathrm{~s}}
$$

Soil porosity is represented by $\epsilon$ while soil tortisity is represented by $\tau$ which can have a value from 1.8 to 6 its value depends mainly on the size of the macro pores. Soil constructivity $\delta$ is mainly related to micro and nano-pores it does not vary that much in value and can be taken to have a value in the range of 0.9 to 1 . The partial atmospheric pressure of carbon dioxide at the soil surface can be taken as $\mathrm{P}_{\mathrm{CO}_{2} \mathrm{~S}}=0.0401[\mathrm{kPa}]$. Carbon dioxide molecular weight is $\mathrm{M}_{\mathrm{CO}_{2}}=44[\mathrm{~kg} / \mathrm{kmole}]$. Furthermore carbon dioxide Mass diffusion $\mathrm{D}_{\mathrm{CO}_{2}}\left[\mathrm{~m}^{2} / \mathrm{s}\right]$ can be found in [84] as a function of temperature. The source term for carbon dioxide is referred to as $\alpha_{\mathrm{CO}_{2}}\left[\mathrm{~kg} / \mathrm{m}^{3} \mathrm{~s}\right]$. Its value for simplicity can considered for a grassland site to be $\alpha_{\mathrm{CO}_{2}}=$ $10^{-3}\left[\mathrm{~kg} / \mathrm{m}^{3} \mathrm{~s}\right]$ while for a forest site can be taken as $\alpha_{\mathrm{CO}_{2}}=10^{-4}\left[\mathrm{~kg} / \mathrm{m}^{3} \mathrm{~s}\right]$. For more accurate values for the carbon dioxide source term for specified categories of soil site locations the researcher is directed to available literature. Furthermore this term changes according to land use changes as mentioned by [85].

In conclusion for the design of an open dynamic chamber which generally encounters carbon dioxide efflux overestimation proposals were presented to tackle such a problem for both calm and windy conditions by using a vented nozzle design that regulates pressure fluctuations [8688]. Another vertical vent design proposed by [89] was used on a closed dynamic chamber to regulate internal pressure on windy sites. The use of a multichannel system of interconnected chambers was another alternative to resolve the pressure disturbances issues [90]. Moreover they opted to use automated pressure compensation counter measures in order to take care of 
the situation when pressure fluctuations occur. However over and under estimation problems were attributed to the chamber design and gas mixture mixing methods.

\subsubsection{Soil Surface Aeration and Pressure Gradient}

The aeration process in general is providing regular charges of air to the small finite soil cavities near the soil surface as shown on Figure 8 . The Aeration process supplies oxygen (which makes up $21 \%$ of the supplied air) and removes carbon dioxide and other gases from the soil, this exchange process happens between the soil and the atmosphere interface. The bulk flow of gas in the soil is a result of the pressure gradient for dynamic chambers, while for static chambers it is related on concentration gradients.

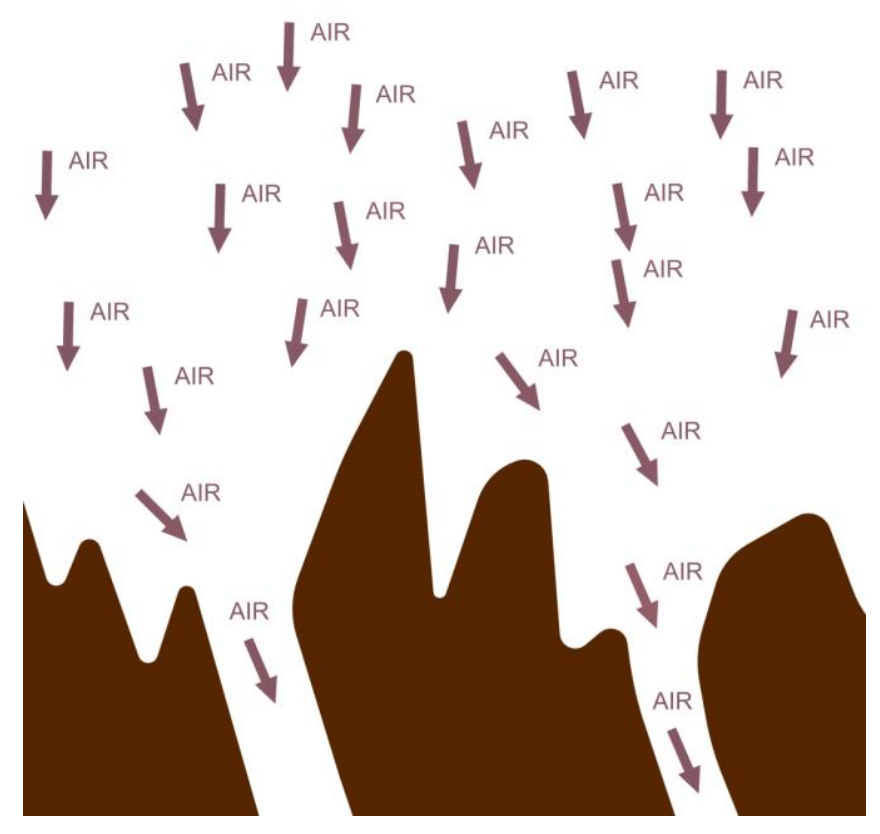

Figure 8: The aeration process through the top soil surface.

Different gases have different friction velocities this is proved mainly using the Eddy covariance method when applied for both carbon dioxide and methane gas as investigated by [91]. The relationship between the friction velocity and efflux has always been an important case to be considered especially for dynamic chambers. Friction velocity $\mathrm{u}_{*}$ for carbon dioxide 
can be calculated using equation (1.36) whereby the carbon dioxide gas density near the soil surface is $\rho_{\mathrm{CO}_{2}}\left[\mathrm{Kg} / \mathrm{m}^{3}\right]$ moreover the surface wall shear stress is $\tau_{\mathrm{w}}[\mathrm{Pa}]$ its value can be found in [92] it all depends on the surface roughness of the location:

$$
\mathrm{u}_{*}=\sqrt{\frac{\tau_{\mathrm{w}}}{\rho_{\mathrm{CO}_{2}}}}
$$

Equation (1.36) can be applied on the soil surface inside the gas volume of the chamber and on the outside soil surface located near to the respiration chambers outer shell. There is a relationship between friction velocity and soil interface pressure this can be found by relating it to a macro-flow case. This can be applied for the first soil layer O horizon which has a thickness of $h=5.08[\mathrm{~cm}]$. Furthermore by using equation (1.37) adapted from [93] whereby it is applied for a distance range of $0<\mathrm{z}<\mathrm{h}$. The partial pressure derivative for a discreet distance $\mathrm{x}$ on the soil surface can be calculated from the following equation:

$$
\frac{\mathrm{dp}}{\mathrm{dx}}=\frac{\mathrm{u}-\mathrm{u}_{*}(1+7927 \mathrm{~h})}{\left(9.7 \times 10^{-9} \mathrm{z}^{2}+15853.6 \mathrm{hz}\right)}
$$

Consequently equation (1.37) can be applied for instance to study the generated suction pressure due to the use of circulation fans inside the gas volume of the chamber. Friction velocity is affected by time of day hence temperature this was shown by [94] a dependence of the Eddy covariance measurement reliability on net radiation was found. During high effective net radiation nights the Eddy covariance method usually underestimates the carbon dioxide efflux produced by the ecosystem. Moreover efflux measurements using the Eddy covariance method were not reliable for nights with extremely low friction velocity. It was found that during low effective radiation nights with friction velocity lower than $0.07[\mathrm{~m} / \mathrm{s}]$ underestimation occurred, while for a case of friction velocity higher than the stated value showed similar measurements between chamber and Eddy covariance method. 
For the purpose of aeration equation (1.38) can be used [95] to estimate the required power for an installed circulation fan inside the respiration chamber. $\mathrm{K}$ is based on chamber geometry, $\mathrm{N}$ is the number of revaluations for the selected fan, $\mathrm{Pu}[\mathrm{w}]$ is the fan power required in a respiration chamber, $\mathrm{Di}[\mathrm{m}]$ is fan diameter, and $\mathrm{Q}\left[\mathrm{m}^{3} / \mathrm{s}\right]$ is the aeration rate (Volume of air supplied per minute divided by the soil volume under the chamber)

$$
P_{g}=K\left(\frac{P_{u}^{2} N_{i}^{3}}{Q^{0.56}}\right)^{0.45}
$$

In conclusion by conducting wind tunnel tests on certain chamber designs or by using ready experimental data the occurring pressure flow frequencies can be calculated. Moreover by linking soil surface pressure frequencies with turbulence frequencies near the soil surface flow infiltration can be calculated. Hence the occurring mass transport can be predicted additionally efflux measurements can be corrected. The Eddy covariance method is not recommended to be used for calm days with low wind speeds. A proposed approach in the research community is the chamber anchoring method it can be used to reduce gas species leakage due to wall shear affects both ways see page 40 .

\subsubsection{Solubility of Carbon Dioxide and Oxygen in Soil Water}

The gas phase of the soil is characterized by the amount or volume and composition of the studied soil sample. The volume fraction of gas generally decreases with depth in a soil profile due to decreasing porosity that takes place as a result of compaction, biological activity and due to the absorbed water content. In the grassland studied case, a volume fraction of gas between $5-15 \%$ is generally considered adequate. The composition of the soil air also varies with depth and time. Due to the free diffusion of the atmospheric components through the soil surface, the composition of the soil air near the surface is almost the same as that in the atmosphere. With depth, the concentration of carbon dioxide increases and that of oxygen 
decreases because of the biological activity in the soil (respiration of plant roots, microorganisms and soil fauna).

The Reason for mentioning the two gases Carbon dioxide and Oxygen is their direct relationship to the respiration quotient. Some scientists have found that re-wetting of peatland in south-east Asia will lead to substantial reductions of net greenhouse gas emissions [96]. Carbon dioxide solubility in the soil water content is governed by Henrys law [97], where $\mathrm{P}_{\mathrm{CO}_{2}}$ $[\mathrm{Pa}]$ is the partial gas pressure of the gas of interest, $\mathrm{K}_{\text {Solu }}\left[\mathrm{mole} / \mathrm{m}^{3} \mathrm{~Pa}\right]$ is the solubility constant and $\mathrm{C}_{\mathrm{w}}\left[\mathrm{mole} / \mathrm{m}^{3}\right]$ is the dissolved gas concentration in Water.

$$
\mathrm{P}_{\mathrm{CO}_{2}}=\mathrm{K}_{\mathrm{Solu}} \mathrm{C}_{\mathrm{w}}
$$

The dissolving of the different gasses, which is to some extent affected by the relation between the soil $\mathrm{pH}$ [98] and the soil stored carbon, this in turn would be to soil total porosity, but it can be small enough to be neglected on the short term measurements. Oxidation-reduction reactions occur under various conditions. Increased carbon dioxide affects the soil $\mathrm{pH}$. Carbon dioxide dissolves in water producing both bicarbonates and carbonates. For more details on the chemistry side of this point, the reader is referred to [99] and [100]. According to the total pressure, species concentration and temperature profile in the soil layers prediction of the gas species solubility can be predicted in the soil pores. This is shown in equation (1.40) whereby the solubility constant of Carbon dioxide decreases with temperature, meaning that during the period of mid-day the carbon dioxide dissolves less. While during the night and early morning Carbon dioxide dissolves more.

$$
\mathrm{K}_{\mathrm{Solu}} \mathrm{C}_{\mathrm{w}} \leq \mathrm{P}_{\mathrm{CO}_{2} \mathrm{~s}}-\alpha_{\mathrm{CO}_{2}} \frac{\mathrm{RT} \tau}{2 \mathrm{D}_{\mathrm{CO}_{2}} \in \delta \mathrm{M}_{\mathrm{CO}_{2}}}\left(\mathrm{z}^{2}-\mathrm{z}_{0}^{2}\right)
$$

Soil temperature changes during hourly bases in a more evident way therefore measurements conducted using chambers for 6 minutes or even for 24 minutes are reliable to know what the 
biological activity of a studied location. Therefore dynamic chambers are recommended for such a study, static chambers are recommended for more of hourly or long duration measurements. This in turn in affect will give some reasons why in Bogs the error of measurement deviations would most probably occur especially on hot days. Due to water evaporation rates are high, in addition to occurring water circulation currents due to the occurrence of buoyancy affects based on temperature gradients in the soil layers.

The conclusion is that you can use static chambers as long as you conduct aeration regularly you release all the stored heat gained from solar radiation, the same for stored cold air during the night. Dynamic chambers also require aeration, this insures a homogenous gas mixture and temperature mixture. Temperature and concentration profiles are necessary to understand the efflux measurements. It is recommended not to have too many circulation fans in the chambers, so that they won't raise the occurring pressure inside the chamber at the soil surface which would resulting from the increase of carbon dioxide solubility. Chamber ventilation is necessary during measurements because entrained gas in the chamber will store heat which in turn would disturb and increase the soil biological activity. A limiting factor for solubility of carbon dioxide is that metabolism is related to temperature occurring in the soil.

\subsection{Respiration Chamber Characteristics}

Each type of experimental apparatus has its own pros and cons. It is the responsibility of the researcher to choose the suitable apparatus that meets the required needs. This depends on the drive of the conducted research. The advantages and disadvantages of using chambers are summarized in the following sections:

\subsubsection{The Advantages of the Chambers}

The main advantages of the chambers can be summarized as follows: 
1. They are relatively easy with no need for highly trained researchers to operate them. For ventilation purposes, the chambers early models open and close manually while the latest models are automated and open and close on the site of deployment [101].

2. They have spatial coverage unlike the EC method where there is no spatial coverage. Thus, air samples are directly measured from a tower located near the studied area.

3. The cost of making a research purpose chamber is relatively low in relation to a commercial one. The cylindrical shell (made from transparent plastics) can be custom built, and the chamber can be put together at the research institute workshop for instance. As long as the chambers has a classical volume shape.

4. Fast measurements and short waiting times can be reached because of the advanced features that uses forced convection for soil efflux measurements [102].

5. By using custom built sensor boxes connected to the chamber entrainment, they can be used for measuring photosynthesis, evapotranspiration, respiration, temperature, dew point temperature, pressure, and light intensity simultaneously. Gas species concentration can also be measured. That can be done through the many available types of gas sensors in the market [103].

6. The chambers can be used in underwater environments to measure carbon dioxide fluxes from seagrass [104] or on peatland locations [105].

7. Cylindrical chambers can be used to measure the efflux resulting from plants and tree branches.

\subsubsection{The Drawbacks of the Chambers}

The main disadvantage of the chambers can be summarized as follows. They were presented in this form to give a clear description to the ideas which varied substantially in topic:

1. The chambers affect the efflux being measured causing collar and pressure problems. The collar problem occurs when the studied soil surface is not flat. The soil that has 
rocks and gravel would also make it difficult to fix the chamber on the soil surface. The pressure problem occurs when a pressure difference takes place between the inside and outside of the chamber causing leakage in and out of the chamber [106].

2. If left at the same site for several months, chambers may change the conditions in the soil, such as grass over growing between inside and outside the chamber. The same applies for increase of plantation cover in a forest site location between two seasons of winter and spring.

3. They are difficult to use in winter especially in critical weather conditions. The accumulation of the snow over the shell leads to the blockage of the solar rays into the chamber affecting the photosynthesis. The chamber might break or deform if surrounding water freezes, crushing its outer shell. In desert locations, extreme heat might cause them to melt down because heat buildup in the chamber would gradually cause the inner chamber to deform and gradually collapse inwards.

4. The differences between the chamber types require calibration. To overcome this problem, there have been many proposals to use cross-calibration functions for the soil carbon dioxide efflux measurement systems [107].

5. It is often cited that a closed chamber underestimates the actual flux due to the mass accumulation or the concentration buildup within the chamber headspace, while a dynamic chamber over estimates the actual flux due to the pressure difference present inside the chamber and caused by drawing an airstream through the chamber. The underestimate bias of closed chambers has been demonstrated in some experiments where concentrations within the chambers headspace showed a nonlinear increase with time, or where the fluxes measured by closed chambers were compared with those measured by dynamic chambers [70]. 
6. Chambers need to be fixed well to the ground because on windy locations they can be blown off.

\subsection{Chambers Anchoring or Insertion into the Soil}

Chamber insertion method is by pushing the chamber on or into the ground. On the other hand the chamber anchoring method is by fixing the chamber onto a fixed base that is inserted into the soil to a predetermined depth, the purpose of such action is to reduce the occurring mass transfer from in and out of the chamber based on external occurring events, to stop leakage. One method of mechanical fixture is through the use of collars presented by [108], or through using the insertion method. An extensive study to quantify chamber pressure effects on soil location was investigated by [109]. Numerical models have also been used to evaluate the anchoring method [110]. Some researchers [108] have found that collar-insertion depth has a potentially long-lasting effect on measured flux rates and needs to be considered when interpreting past data and planning future studies. They demonstrated the need either to avoid insertion or to measure the amount of cut roots when inserting collars, and for the deployment of less intrusive techniques such as stable isotopes or membrane techniques. The chamber clamp method has been applied for a dynamic chamber case for a grassland site, while mixing fans that blow air in a perpendicular direction to the soil surface were used [20]. The test results strongly suggest that, to get accurate measurements of soil respiration, collar insertion is strongly recommended. After a while, scientist started to investigate the insertion depth applicability, as done by [111] where the collar was pushed inside the soil to a distance ranged between 5 and $8 \mathrm{~cm}$. Others [112] used the anchoring method to a depth of 6 to $8 \mathrm{~cm}$ the selected depth purpose is to ensure complete entrainment. Other researchers tested the anchoring depth of $10 \mathrm{~cm}$ [113]. Reference [114] stated that 75\% of the carbon dioxide efflux comes from the top $20 \mathrm{~cm}$ of the soil. 
Reliability of the chamber systems was not related to the measurement principle as stated by [24], good results can be achieved with both steady-state and unsteady-state chambers. However, even the same chambers with different collar designs showed highly variable results. The general trend seemed to be that non-steady-state non-through-flow chambers systematically underestimated measurements by $4-14 \%$. Likewise no significant differences between through-flow chambers were observed.

In a grassland study [115] anchors have been left for over 10 years. One advantage of leaving anchors in place for long periods of time is that soil disturbance and root damage are minimized. The problem with anchored chambers is that during a rain fall they create ponds of water around the chamber. Chamber-soil contact mode has a significant impact on the efflux measurement as mentioned by [107] this was observed when using collar or insertion mode. The resulting general high efflux values obtained by using the "insertion" mode can be explained through the following three hypotheses:

1. Diffusion conditions would change in the litter and near surface mineral layers while inserting the chamber. When insertion is conducted the soil surface litter is disturbed [116], therefore the vertical diffusion coefficient is increased resulting in an initial jump of efflux measurements.

2. On a long-term study, carbon dioxide efflux measurements are affected after a collar placement has been installed, due to fine plant roots getting cut during the process

3. When using collar or drilled ring method a distance is created between the structural outer shell and the soil surface. When a blowing fan is used the boundary layer created on the soil surface is thinner for a collar method than that of a drilled ring, this resulted in an increase in carbon dioxide efflux measurements by the used insertion method [117]. 
In conclusion static chambers are practical for use for a long period deployment. A way around this problem is to see what correction factor that can be obtained, and when using the anchoring method. So for example to derive such a factor experimentally the researcher can measure the flux without having an anchoring method at steady conditions and then check the difference in flux resulted from the anchoring.

\subsection{The Role of Soil pH/Bacteria on Carbon Dioxide Production and Transport in Soil}

Soil $\mathrm{pH}$ is a measure of its acidity or alkalinity and it is expressed in a numerical scale. The scale goes from 0.0 to 14.0 with 0.0 being the most acid and 14.0 being the most alkaline. Researchers have explored the relationship between soil efflux and $\mathrm{pH}$ and have found that soil $\mathrm{pH}$ and relative root mass are found as important factors to describe spatial variation of soil carbon dioxide emission due to vegetation productivity and microbial activity spans [118]. Speaking from a abiotic perspective, by knowing the soil site $\mathrm{pH}$, the mineral constituents of the soil sample can be estimated in a qualitative manner [119]. On the other hand from a biotic (biological) perspective looking closely at a bacteria cell, we find that it contains several hundred enzymes, most of which are $\mathrm{pH}$ dependent and are associated with cell components, such as membranes. Moisture porosity is of importance in relation to $\mathrm{pH}$ because it reflects the contained water content of the studied soil on location, studies have showed that moisture porosity till a value of $21 \%$ increases $\mathrm{CO} 2$ efflux, then any increase after that value results in a decline in fluxes[120]. Soil $\mathrm{pH}$ plays a major role because it influences several soil factors affecting plant growth [121] which can affect the carbon dioxide measurement, such as:

1. Nutrient leaching occurs if there are big concentration gradients in the soil layers, leaching intensity decreases with depth as a result of water plant uptake and evaporation [122]. Plant nutrients leach out of soils with a $\mathrm{pH}$ below 5.0 in a more rapid manner than from soils with values between 5.0 and 7.5. Leaching effects have been studied for grassland and forest sites [98], only on long duration time scales leaching effects can 
be seen on the carbon dioxide production by the plants and the bacteria, because it directly affects the location carbon pool. Moreover, excess rain fall [123] does affect the soil leaching only if rainfall exceeds a rate of $6.35 \mathrm{~mm} / \mathrm{h}$.

2. Nutrients availability affects carbon dioxide production in the autotropic and heterotropic process [124]. Plant nutrients are generally most available to plants in the $\mathrm{pH}$ range from 5.5 to 6.5 . For most plants, the optimum $\mathrm{pH}$ range is from 5.5 to 7.0 , but some plants will grow in a more acid soil or may require a more alkaline level. That is why the researcher has to make a survey of the existing plants on the studied soil surface. Most of the known bacteria species grow within a $\mathrm{pH}$ range from 4 to 9 while in the case of fungi they are acidophilic, with a pH range from 4 to 6 [70].

3. Toxic elements, if found, cause a decrease in the carbon dioxide production [125] because they act as inhibitors for growth and metabolism for bacteria, for plants they also have unwanted affects [126]. Therefore aluminium and manganese should be in the safe limit depending on type of plant, this has been proved for Rye grass [127].

4. The acidity or alkalinity of the soil plays a role in changing the permeability (soil structure) on the long term basis, where new pores are created due to the consumption of the chemical constituents and other pores are closed due to new chemical constituents being created. The rate of this change ranges from the micropore to the macropore scale depending on the intensity of the process.

In conclusion chambers should preserve as much as possible the carbon pool of the location. That is by the chamber not contributing directly or indirectly to the soil leaching effect. Unfortunately extreme weather conditions do occur and cannot be controlled, keeping in mind that depends on the site of study. High blowing winds or sudden temperature rise would increase the water evaporation rate causing soil leaching. Nutrient leaching for soil also occurs 
if plant root growth is disrupted inside or outside the chamber. Avoiding the creation of water pools around the chamber is recommended because it disturbs the original site $\mathrm{pH}$.

Bacteria play an important role in the decomposition of the organic materials, especially in the early stages of the decomposition when the moisture levels are high. In the later stages of decomposition, fungi tend to dominate. Soil bacteria metabolism is related either to aerobic or anaerobic conditions which links up to soil parameters of porosity and permeability, this proves why there is an important factor of aeration or regular watering.

Microorganisms abound in the soil and are critical to the decomposing of the organic residues and to the recycling of the soil nutrients. The Bacteria are the smallest and most hardy microbe in the soil and can survive under harsh or changing soil conditions. The bacteria are important in producing polysaccharides that cement sand, silt, and clay particles together to form microaggregates and improve the soil structure. Their activity can increase carbon dioxide flux [128]. The decomposition rates in the soil under elevated carbon dioxide would be slower, resulting in an increased carbon storage in the soil [129]. Bacteria growth phases have been characterized and modelled by [130]. A new Growth of bacterial cultures' 50 years on: towards an uncertainty principle instead of constants in bacterial growth kinetics [131]. Bacteria population goes through 5 phases in relation to time these are as follows: lag, exponential, deceleration, stationary and death phase this is shown in Figure 9 : 


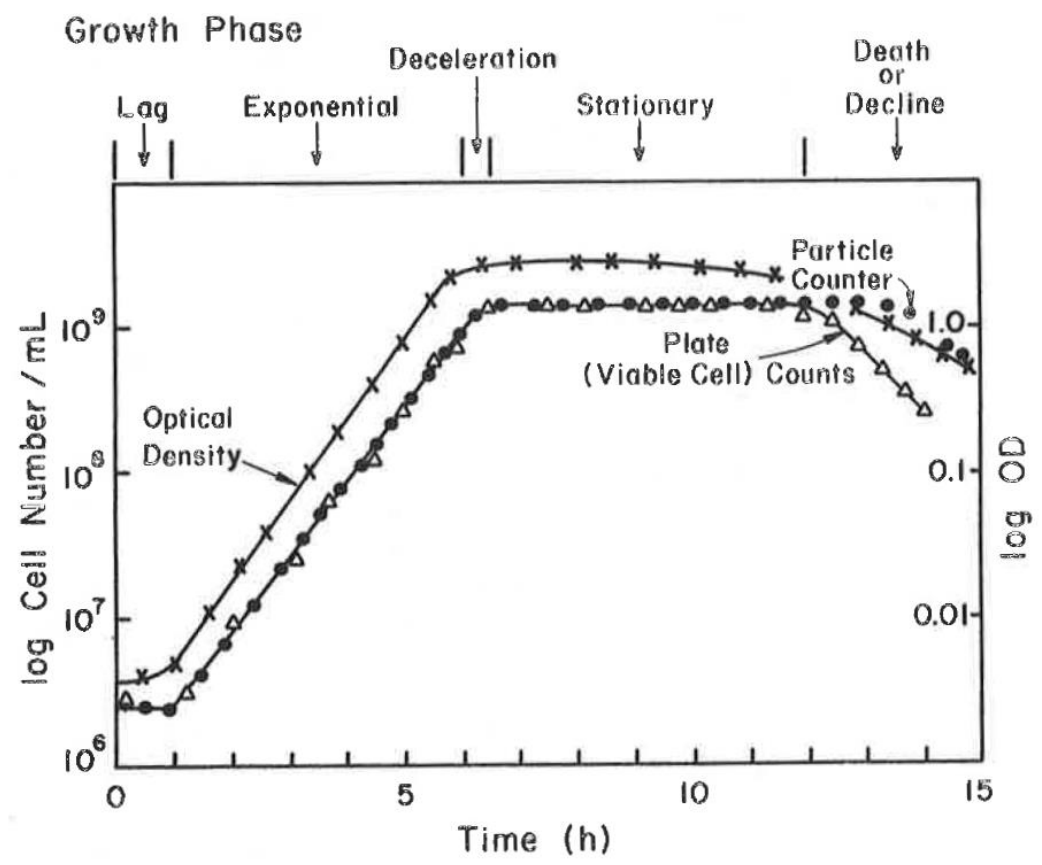

Figure 9: Typical growth curve for a bacterial population. Note that the phase of growth depends on the parameter used to monitor growth [132].

This drives us to the conclusion that one of the main challenges of site location of study is that bacteria cultures are distributed in a random manner and identifying at which stage the soil bacteria is going through is difficult in addition to population distribution. Hence one of the recommended methods of modelling growth and population is by linking these parameters to soil layers through the use of statistical and probability distribution functions.

The carbon dioxide efflux is related to the average value of the log number of bacteria, for each stage of growth cycle. Experimental tests have been conducted through integrated evaluation of soil quality after the incorporation of organic matter and microorganisms [133] this is illustrated in Figure 10. Furthermore the change of carbon dioxide efflux is related to date of incubation. 


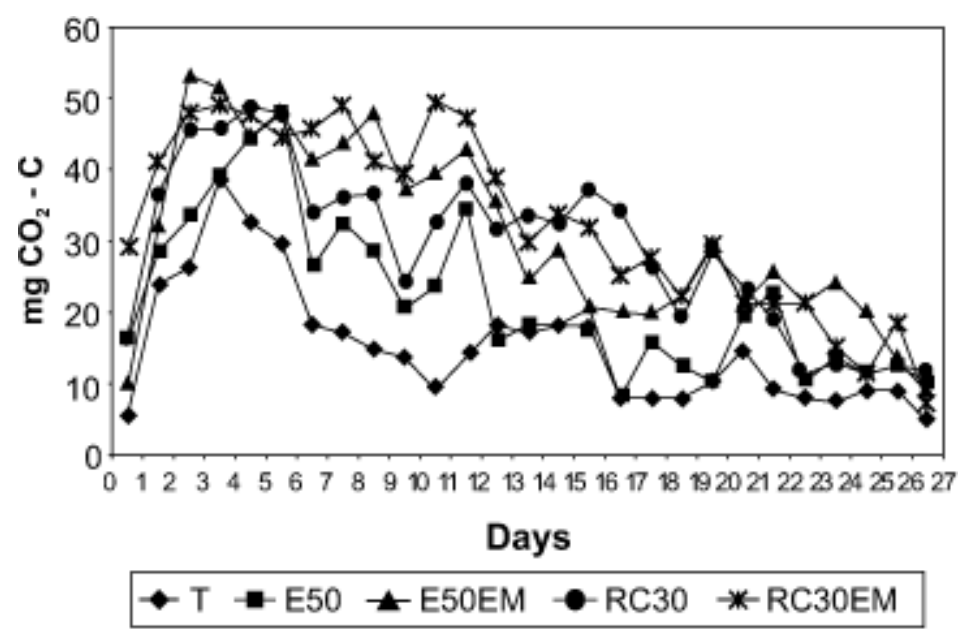

Figure 10: Determination of total microbial activity $\left(\mathbf{m g C O}_{2}-\mathbf{C}\right)$ in sample of soil mixed with different types of organic matter, incubated at $25^{\circ} \mathbf{C}[133]$.

There is also an important relationship between bacteria cultures and temperature stated in [134], This has been modelled by for the biokinetc temperature range [135]. At some instances it is been reported that by disturbing the soil at a site of interest a jump in soil flux dose occur [116]. That's resulted in the adoption of the soil tilling method on agricultural locations of farm lands, because with the aeration of the soil biological activity is stimulated .The air of the soil is made up of the same basic constituents as the atmospheric air; however, the ratios of various gases are different and more variable due to that diffusion is the dominant factor for mass transport in soil cavities. Bacteria also gets transported within water flows, when rain storms hit the soil site location [123], this has been proved for an agricultural site, where crop fertilizers where used that contained bacteria.

It is very important to point out that almost all the void volume of the soil can be occupied by either air or water. The amount of air in the soil is thus inversely related to the amount of water present. When the air content is around $50 \%$ or more of the void volume, the soil is considered to be aerobic and oxidation reactions predominate. When the void volume is occupied by water, 
the soil becomes anaerobic and reducing reactions predominate. The ratios of volume fraction distribution for masses, Soil atmosphere composition under aerobic and anaerobic conditions.

The Aerobic bacteria are those that need oxygen. This means that they are related to the volume of the gas pores, so aerobes tend to dominate when the soil is well drained as an example for a desert soil location. Anaerobes, on the other hand, are the bacteria that do not need oxygen and may find it toxic, these kinds of bacteria can be found in ponds, wetlands, peatland respiration, respiration chambers have also been used in ponds [136]. This means that they are related to the volume of liquid pores.

The oxidation reactions in the soil, particularly those carried out by the microorganisms and plant roots increase the amount of carbon dioxide in the soil air to 10 times or more the concentration in the atmospheric air. As a result of that the oxygen content will be proportionally decreased. When the soil void volume is almost or completely filled with water, the remaining trapped and dissolved oxygen is quickly utilized by the organisms and the oxygen content of any remaining gas will become zero. The soil will then become anaerobic and the reducing conditions will prevail. The Aerobic bacteria are those that need oxygen. This means that they are related to the volume of the gas pores, so aerobes tend to dominate when the soil is well drained. Anaerobes, on the other hand, are the bacteria that do not need oxygen and may find it toxic. This means that they are related to the volume of liquid pores. In this studied attention is paid to both the aerobes and the anaerobes because of their relationship with porosity and permeability.

Microbial activity is the flux of carbon through a biotic system. Microbial activity is normalized with growth microbial activity to give the relative microbial activity. The relative microbial activity in any site is related to the soil porosity. This reflects the rate of production of carbon dioxide for both anaerobic and aerobic conditions. There is a common conceptual relationship 
[137] that shows where the soil carbon dioxide efflux becomes slow under dry conditions. It reaches a maximal rate at the intermediate soil moisture level, and decreases at high soil moisture content when anaerobic conditions prevail to depress aerobic microbial activity. The optimum relative microbial activity is usually somewhere near field capacity.

In conclusion, lab based analysis of the soil sample is required to identify the soil bacteria, and then the respiration quotient can be found. The focus here will only be on aerobic bacteria due to its strong relationship with aeration process. The aeration process [132] in the respiration chamber dose not consume all the available oxygen in the chamber. Respiration quotient differs for one type of bacteria to another meaning that each type of bacteria has different stoichiometric coefficients. In general the process is represented in equation (1.41):

$$
\mathrm{C}_{\mathrm{w}} \mathrm{H}_{\mathrm{x}} \mathrm{O}_{\mathrm{y}} \mathrm{N}_{\mathrm{z}}+\mathrm{aO}_{2}+\mathrm{bH}_{\mathrm{g}} \mathrm{O}_{\mathrm{h}} \mathrm{N}_{\mathrm{i}} \rightarrow \mathrm{cCH}_{\alpha} \mathrm{O}_{\beta} \mathrm{N}_{\delta}+\mathrm{dCO}_{2}+\mathrm{eH}_{2} \mathrm{O}
$$

The carbon balance $\mathrm{C}$ shown in equation (1.42) is found from equation (1.41):

$$
\mathrm{w}=\mathrm{c}+\mathrm{d}
$$

The hydrogen $\mathrm{H}$ balance shown in equation (1.43) is found from equation (1.41):

$$
\mathrm{x}+\mathrm{bg}=\mathrm{c} \alpha+2 \mathrm{e}
$$

The oxygen $\mathrm{O}$ balance shown in equation (1.44) is found from equation (1.41):

$$
y+2 a+b h=c \beta+2 d+e
$$

The nitrogen $\mathrm{N}$ balance shown in equation (1.45) is found from equation (1.41):

$$
\mathrm{z}+\mathrm{bi}=\mathrm{c} \delta
$$

By solving simultaneously the system of equations (1.42 to 1.45) for a specified type of bacteria: $\mathrm{C}_{w} \mathrm{H}_{\mathrm{x}} \mathrm{O}_{\mathrm{y}} \mathrm{N}_{\mathrm{z}}$. The Respiration quotient for a specific type of bacteria $\mathrm{n}$ can be found 
using equation (1.46). Where the ratio is in $\mathrm{d}[\mathrm{mole} / \mathrm{s}]$ of produced carbon dioxide over a [mole/s] of consumed oxygen:

$$
\mathrm{RQ}_{\mathrm{n}}=\frac{\mathrm{CO}_{2} \text { Produced }}{\mathrm{O}_{2} \text { Consumed }}=\frac{\mathrm{d}}{\mathrm{a}}
$$

The individual efflux from a single soil microbial cell $\mathrm{ef}_{\text {mcell }}\left[\mathrm{mole} / \mathrm{m}^{2} \mathrm{~s}\right]$ can be calculated from equation (1.47). This equation was proposed by [138] where $C_{0}\left[\mathrm{~mole} / \mathrm{m}^{3}\right]$ is the solute concentration at the cell surface, $\mathrm{C}_{\mathrm{b}}\left[\mathrm{mole} / \mathrm{m}^{3}\right]$ is the solute concentration in bulk soil is, $\mathrm{D}_{0}\left[\mathrm{~m}^{2} / \mathrm{s}\right]$ is diffusivity, $\mathrm{K}_{\mathrm{b}}$ is constant, $\theta$ is the volumetric water content, and $\mathrm{S}[\mathrm{m}]$ is the diameter of a bacterial cell:

$$
\mathrm{ef}_{\mathrm{mcell}}=\frac{\left(\mathrm{C}_{0}-\mathrm{C}_{\mathrm{b}}\right) \mathrm{D}_{0} \mathrm{~K}_{\mathrm{b}} \theta^{3}}{\mathrm{~S}}
$$

In particular the model can be extended to calculate the total efflux $\mathrm{ef}_{\mathrm{BP}}\left[\mathrm{mole} / \mathrm{m}^{2} \mathrm{~s}\right]$ for a bacterial community. Where by the total number of bacterial cells $\mathrm{N}_{\mathrm{b}}$ is for a specified area or volume of a soil sample. Then for simplicity this can be applied to the whole soil volume located beneath the respiration chamber:

$$
\mathrm{ef}_{\mathrm{BP}}=\mathrm{N}_{\mathrm{b}} \mathrm{ef}_{\text {mcell }}
$$

The respiration quotient of the whole bacterial activity at one location is in equation (1.49) this represented by the summation $\mathrm{RQ}_{\mathrm{Total}}$ Bacteria of all respiration quotients.

$$
\mathrm{RQ}_{\text {Total Bacteria }}=\sum_{1}^{n} \mathrm{RQ}_{\mathrm{n}}=\mathrm{RQ}_{1}+\mathrm{RQ}_{2}+\cdots \mathrm{RQ}_{\mathrm{n}}
$$

To calculate the total generated efflux $\mathrm{ef}_{\text {Total Bacteria }}\left[\mathrm{mole} / \mathrm{m}^{2} \mathrm{~s}\right]$ from aerobic bacteria at a specified location soil surface area $A_{\text {Soil Area }}\left[\mathrm{m}^{2}\right]$ : 


$$
\mathrm{ef}_{\text {Total Bacteria }}=\frac{\left[\text { Total Consumed } \mathrm{O}_{2}\right] \cdot \mathrm{RQ}_{\text {Total Bacteria }}}{\mathrm{A}_{\text {Soil Area }}}
$$

Soil bacteria types can be found in [121] also in [139] this helps in finding the $\mathrm{C}_{w} \mathrm{H}_{x} \mathrm{O}_{y} \mathrm{~N}_{z}$ for the bacteria of interest. The main focus on aerobic bacteria is because the respiration chambers measure the biological activity of the top layers of the soil. Respiration chambers have an impact on bacterial activity because they do disturb the bacteria cultures distributed on the location. Chemical reactions are governed by temperature therefore the efflux in equation (1.50) is a function to soil temperature.

It has been noted by researchers that soil temperature affects root growth in parallel soil nutrients also contribute [140], therefore there should be some heat balance achieved in the respiration chamber gas and the soil volume beneath the chamber. Chambers at some points have negative effects on stem growth especially in rain forests [141] but also this can allow us to identify the complex interactions between canopy foliar and reproductive dynamics, stem growth, soil processes, and nutrient fluxes as exclusion provokes progressively larger soil moisture deficits.

Using closed dynamic chambers, some researchers [142] have pointed out that there is a relationship between soil porosity, carbon dioxide flux and root rhizospheres. That was proved through data measurements collected from the sites of several forests during dry seasons, these showed less activity of the root rhizospheres. Root respiration was found to depend mainly on the soil fertility, which has been discussed extensively in the classical references of [143] and [144]. One concern according the respiration chambers use is that they should minimize their effect on the transport of nutrients, and nutrient exchange with plant roots. In conclusion temperature affects the activity therefore there has to be some balance between the inner temperature of the chamber and atmospheric outer temperature. 


\subsection{Conclusion}

Infrared gas sensors look promising to be used on new designs of respiration chambers. Likewise they should be used in parallel with other sensors to monitor the process closely from all other physical parameters. Especially that change in surrounding pressure internal temperature and air moisture content affects the directly or indirectly the measurement process. The chambers gas mixture should be mixed to create a homogenous mixture. Furthermore the sample should be measured at a location predetermined from tests. That is because as it was proved from other used chamber designs in the scientific community that mixture concentration inside the chamber gas volume changes from one location to another especially in the vertical direction. Pressure equilibrium between the inside and outside the chamber is a requirement therefore internal pressure affects must be considered. Blowing winds on the soil surface produce a pressure gradient in the soil top layer consequently that changes the pressure profile inside the soil layer. Hence the proposed model can be used to predict the soil aeration rate in relation to blowing wind velocities. Moreover the pressure profile with the required concentration and temperature profile shows the carbon dioxide solubility in the different soil layers. The respiration chamber characteristics can be used as a guide to develop better chambers. By surveying the different soil bacteria in the soil site location and finding their respiration quotient of each type. Furthermore by surveying the population of bacteria in a soil sample and approximating the bacteria surface area the produced efflux from each bacteria community can be calculated.

\subsection{Acknowledgments}

We would like to thank Dr Torsten Howind, Dr Mohammad Afzal and Cristina Rodriguez for their regular constructive thoughts and conservations relating to the chemical, meteorological, geological and biological side of the project. We would also like to thank all members of the Institute of Engineering and Energy Technologies (IEET) and Institute of Thin Films, Sensors 
\& Imaging at the University of UWS in providing the necessary facilities to conduct such research. 


\section{References}

1. Levine, J.S., Measurement of nitrogen oxide emissions from an agricultural soil with a dynamic chamber system. Journal of geophysical research, 1999. 104(D1): p. 16091619.

2. Cambardella, C., et al., Field-scale variability of soil properties in central Iowa soils. Soil Science Society of America Journal, 1994. 58(5): p. 1501-1511.

3. Kutsch, W.L., M. Bahn, and A. Heinemeyer, Soil carbon dynamics: an integrated methodology2009: Cambridge University Press.

4. Raich, J.W. and C.S. Potter, Global patterns of carbon dioxide emissions from soils. Global Biogeochemical Cycles, 1995. 9(1): p. 23-36.

5. Bazzaz, F.A., The response of natural ecosystems to the rising global $\mathrm{CO} 2$ levels. Annual review of ecology and systematics, 1990: p. 167-196.

6. Omer, A.M., Energy, environment and sustainable development. Renewable and sustainable energy reviews, 2008. 12(9): p. 2265-2300.

7. Omer, A.M., Power, people and pollutions. Renewable and sustainable energy reviews, 2008. 12(7): p. 1864-1889.

8. Asif, M. and T. Muneer, Energy supply, its demand and security issues for developed and emerging economies. Renewable and sustainable energy reviews, 2007. 11(7): p. $1388-1413$.

9. Solangi, K., et al., A review on global solar energy policy. Renewable and sustainable energy reviews, 2011. 15(4): p. 2149-2163.

10. Pohekar, S. and M. Ramachandran, Application of multi-criteria decision making to sustainable energy planning - a review. Renewable and sustainable energy reviews, 2004. 8(4): p. 365-381. 
11. Lei, M., et al., A review on the forecasting of wind speed and generated power. Renewable and sustainable energy reviews, 2009. 13(4): p. 915-920.

12. Stambouli, A.B. and E. Traversa, Fuel cells, an alternative to standard sources of energy. Renewable and sustainable energy reviews, 2002. 6(3): p. 295-304.

13. Bugaje, I., Renewable energy for sustainable development in Africa: a review. Renewable and sustainable energy reviews, 2006. 10(6): p. 603-612.

14. Omer, A.M., Green energies and the environment. Renewable and sustainable energy reviews, 2008. 12(7): p. 1789-1821.

15. Sumathi, S., S. Chai, and A. Mohamed, Utilization of oil palm as a source of renewable energy in Malaysia. Renewable and sustainable energy reviews, 2008. 12(9): p. 24042421.

16. Panwar, N., S. Kaushik, and S. Kothari, Role of renewable energy sources in environmental protection: a review. Renewable and sustainable energy reviews, 2011. 15(3): p. 1513-1524.

17. Niven, R.K., Ethanol in gasoline: environmental impacts and sustainability review article. Renewable and sustainable energy reviews, 2005. 9(6): p. 535-555.

18. Pumpanen, J., et al., Comparison of different chamber techniques for measuring soil $\mathrm{CO}<\mathrm{sub}>2</$ sub $>$ efflux. Agricultural and Forest Meteorology, 2004. 123(3): p. 159176.

19. Eckley, C., et al., The influence of dynamic chamber design and operating parameters on calculated surface-to-air mercury fluxes. Atmospheric Environment, 2010. 44(2): p. 194-203.

20. Pape, L., et al., An automated dynamic chamber system for surface exchange measurement of non-reactive and reactive trace gases of grassland ecosystems. Biogeosciences, 2009. 6(3): p. 405-429. 
21. Heinemeyer, A. and N.P. McNamara, Comparing the closed static versus the closed dynamic chamber flux methodology: Implications for soil respiration studies. Plant and soil, 2011. 346(1-2): p. 145-151.

22. Christiansen, J.R., et al., Assessing the effects of chamber placement, manual sampling and headspace mixing on $\mathrm{CH} 4$ fluxes in a laboratory experiment. Plant and soil, 2011. 343(1): p. 171-185.

23. Martin, J.G., P.V. Bolstad, and J.M. Norman, A carbon dioxide flux generator for testing infrared gas analyzer-based soil respiration systems. Soil Science Society of America Journal, 2004. 68(2): p. 514-518.

24. Pumpanen, J., et al., Comparison of different chamber techniques for measuring soil CO2 efflux. Agricultural and Forest Meteorology, 2004. 123(3): p. 159-176.

25. Fan, Z., J.C. Neff, and N.P. Hanan, Modeling pulsed soil respiration in an African savanna ecosystem. Agricultural and Forest Meteorology, 2015. 200: p. 282-292.

26. Liang, N., G. Inoue, and Y. Fujinuma, A multichannel automated chamber system for continuous measurement of forest soil CO2 efflux. Tree physiology, 2003. 23(12): p. $825-832$.

27. Wohlfahrt, G., et al., Quantifying nighttime ecosystem respiration of a meadow using eddy covariance, chambers and modelling. Agricultural and Forest Meteorology, 2005. 128(3): p. 141-162.

28. Drewitt, G., et al., Measuring forest floor CO 2 fluxes in a Douglas-fir forest. Agricultural and Forest Meteorology, 2002. 110(4): p. 299-317.

29. Rayment, M. and P. Jarvis, An improved open chamber system for measuring soil CO2 effluxes in the field. Journal of geophysical research, 1997. 102(D24): p. 28779-28,784. 
30. Pongracic, S., M. Kirschbaum, and R. Raison, Comparison of soda lime and infrared gas analysis techniques for in situ measurement of forest soil respiration. Canadian Journal of Forest Research, 1997. 27(11): p. 1890-1895.

31. Widén, B. and A. Lindroth, A calibration system for soil carbon dioxide-efflux measurement chambers. Soil Science Society of America Journal, 2003. 67(1): p. 327334.

32. Wharton, S. and R. Pyles Pressure Pumping Effects on Soil Efflux Measurements of CO2. 2008.

33. Aubinet, M., T. Vesala, and D. Papale, Eddy covariance: a practical guide to measurement and data analysis2012: Springer Science \& Business Media.

34. Moncrieff, J.B., et al., A system to measure surface fluxes of momentum, sensible heat, water vapour and carbon dioxide. Journal of Hydrology, 1997. 188: p. 589-611.

35. Drewitt, G., et al., Measuring forest floor $\mathrm{CO} 2$ fluxes in a Douglas-fir forest. Agricultural and Forest Meteorology, 2002. 110(4): p. 299-317.

36. Goulden, M.L., et al., Measurements of carbon sequestration by long-term eddy covariance: Methods and a critical evaluation of accuracy. Global Change Biology, 1996. 2(3): p. 169-182.

37. Butnor, J.R. and K.H. Johnsen, Calibrating soil respiration measures with a dynamic flux apparatus using artificial soil media of varying porosity. European Journal of Soil Science, 2004. 55(4): p. 639-647.

38. Sanci, R., H.O. Panarello, and H.A. Ostera, Assessment of soil moisture influence on CO2 flux: a laboratory experiment. Environmental geology, 2009. 58(3): p. 491-497.

39. Conen, F. and K. Smith, An explanation of linear increases in gas concentration under closed chambers used to measure gas exchange between soil and the atmosphere. European Journal of Soil Science, 2008. 51(1): p. 111-117. 
40. Schulze, E.-D., A new type of climatized gas exchange chamber for net photosynthesis and transpiration measurements in the field. Oecologia, 1972. 10(3): p. 243-251.

41. Systems, P. SRC-1 Soil efflux Respiration Chamber 2015; Available from: http://ppsystems.com/soil-and-canopy-flux/.

42. Systems, P. CPY-4 Model Chamber. 2015; Available from: http://ppsystems.com/wpcontent/uploads/EDSCPY41.pdf.

43. Bergman, T.L., F.P. Incropera, and A.S. Lavine, Fundamentals of heat and mass transfer2011: John Wiley \& Sons.

44. Ham, J.M. and G. Kluitenberg, Modeling the effect of mulch optical properties and mulch-soil contact resistance on soil heating under plastic mulch culture. Agricultural and Forest Meteorology, 1994. 71(3): p. 403-424.

45. Koorevaar, P., G. Menelik, and C. Dirksen, Elements of soil physics. Vol. 13. 1983: Elsevier.

46. Marshall, T.J., J.W. Holmes, and C.W. Rose, Soil physics1996: Cambridge University Press.

47. Najafpour, G., Biochemical engineering and biotechnology2006: Elsevier.

48. Ozgener, O., L. Ozgener, and J.W. Tester, A practical approach to predict soil temperature variations for geothermal (ground) heat exchangers applications. International Journal of Heat and Mass Transfer, 2013. 62: p. 473-480.

49. Graf, A., et al., Measurement depth effects on the apparent temperature sensitivity of soil respiration in field studies. Biogeosciences Discussions, 2008. 5(3): p. 1867-1898.

50. Parkin, T.B. and T.C. Kaspar, Temperature controls on diurnal carbon dioxide flux. Soil Science Society of America Journal, 2003. 67(6): p. 1763-1772. 
51. Ozgener, O., L. Ozgener, and D.Y. Goswami, Experimental prediction of total thermal resistance of a closed loop EAHE for greenhouse cooling system. International Communications in Heat and Mass Transfer, 2011. 38(6): p. 711-716.

52. Fang, C. and J. Moncrieff, The dependence of soil CO 2 efflux on temperature. Soil Biology and Biochemistry, 2001. 33(2): p. 155-165.

53. Monson, R.K., et al., Winter forest soil respiration controlled by climate and microbial community composition. Nature, 2006. 439(7077): p. 711-714.

54. Camarda, M., S. Gurrieri, and M. Valenza, Effects of soil gas permeability and recirculation flux on soil $\mathrm{CO} 2$ flux measurements performed using a closed dynamic accumulation chamber. Chemical Geology, 2009. 265(3): p. 387-393.

55. Reth, S., M. Reichstein, and E. Falge, The effect of soil water content, soil temperature, soil pH-value and the root mass on soil CO2 efflux-A modified model. Plant and soil, 2005. 268(1): p. 21-33.

56. White, F.M. and I. Corfield, Viscous fluid flow. Vol. 3. 2006: McGraw-Hill New York.

57. Powers, H.H., et al., A dynamic soil chamber system coupled with a tunable diode laser for online measurements of $\delta 13 \mathrm{C}, \delta 18 \mathrm{O}$, and efflux rate of soil-respired $\mathrm{CO} 2$. Rapid Communications in Mass Spectrometry, 2010. 24(3): p. 243-253.

58. Subke, J.A., M. Reichstein, and J.D. Tenhunen, Explaining temporal variation in soil $\mathrm{CO} 2$ efflux in a mature spruce forest in Southern Germany. Soil Biology and Biochemistry, 2003. 35(11): p. 1467-1483.

59. Tagesson, T., Seasonal variation and controlling factors of soil carbon effluxes in six vegetation types in southeast of Sweden2006: SKB.

60. Yuste, J.C., et al., Soil respiration in a mixed temperate forest and its contribution to total ecosystem respiration. Tree physiology, 2005. 25(5): p. 609-619. 
61. Falge, E., et al., Gap filling strategies for defensible annual sums of net ecosystem exchange. Agricultural and Forest Meteorology, 2001. 107(1): p. 43-69.

62. Pilegaard, K., et al., Two years of continuous $\mathrm{CO} 2$ eddy-flux measurements over a Danish beech forest. Agricultural and Forest Meteorology, 2001. 107(1): p. 29-41.

63. Nay, S.M., K.G. Mattson, and B.T. Bormann, Biases of chamber methods for measuring soil CO2 efflux demonstrated with a laboratory apparatus. Ecology, 1994. 75(8): p. 2460-2463.

64. Fahey, T.J., et al., Soil respiration and soil carbon balance in a northern hardwood forest ecosystem. Canadian Journal of Forest Research, 2005. 35(2): p. 244-253.

65. Ross, F.C., Concepts in biology2003: McGraw-Hill College.

66. Feng, X., et al., Distribution, accumulation, and fluxes of soil carbon in four monoculture lysimeters at San Dimas Experimental Forest, California. Geochimica et cosmochimica acta, 1999. 63(9): p. 1319-1333.

67. Takle, E.S., et al., Influence of high-frequency ambient pressure pumping on carbon dioxide efflux from soil. Agricultural and Forest Meteorology, 2004. 124(3): p. 193206.

68. Flechard, C., et al., Temporal changes in soil pore space $\mathrm{CO} 2$ concentration and storage under permanent grassland. Agricultural and Forest Meteorology, 2007. 142(1): p. 6684.

69. Davidson, E., et al., Minimizing artifacts and biases in chamber-based measurements of soil respiration. Agricultural and Forest Meteorology, 2002. 113(1): p. 21-37.

70. Luo, Y. and X. Zhou, Soil respiration and the environment2006: Academic press.

71. Gu, L., et al., Objective threshold determination for nighttime eddy flux filtering. Agricultural and Forest Meteorology, 2005. 128(3): p. 179-197.

72. Yiqi, L. and X. Zhou, Soil respiration and the environment2010: Academic press. 
73. Townend, J., Effects of elevated carbon dioxide and drought on the growth and physiology of clonal Sitka spruce plants (Picea sitchensis (Bong.) Carr.). Tree physiology, 1993. 13(4): p. 389-399.

74. Tagesson, T., Calibration and analysis of soil carbon efflux estimates with closed chambers at Forsmark and Laxemar2006: SKB.

75. Baldocchi, D.D. and T.P. Meyers, Trace gas exchange above the floor of a deciduous forest. 1. Evaporation and CO2 efflux. J. Geophys. Res, 1991. 96(D4): p. 7271-7285.

76. Lund, C., et al., The effects of chamber pressurization on soil-surface $\mathrm{CO} 2$ flux and the implications for NEE measurements under elevated CO2. Global Change Biology, 1999. 5(3): p. 269-281.

77. Kimball, B. and E. Lemon, Spectra of air pressure fluctuations at the soil surface. Journal of geophysical research, 1970. 75(33): p. 6771-6777.

78. Takle, E.S., et al., High-frequency pressure variations in the vicinity of a surface $\mathrm{CO} 2$ flux chamber. Agricultural and Forest Meteorology, 2003. 114(3): p. 245-250.

79. Kimball, B. and E. Lemon, Theory of soil air movement due to pressure fluctuations. Agricultural meteorology, 1972. 9: p. 163-181.

80. Massman, W. and X. Lee, Eddy covariance flux corrections and uncertainties in longterm studies of carbon and energy exchanges. Agricultural and Forest Meteorology, 2002. 113(1-4): p. 121-144.

81. Mahrer, Y., A numerical model for calculating the soil temperature regime under transparent polyethylene mulches. Agricultural Meteorology, 1980. 22(3): p. 227-234.

82. Sui, H.-j., D.-c. Zeng, and F.-z. Chen, A numerical model for simulating the temperature and moisture regimes of soil under various mulches. Agricultural and Forest Meteorology, 1992. 61(3): p. 281-299. 
83. Bahn, M., et al., Soil respiration in European grasslands in relation to climate and assimilate supply. Ecosystems, 2008. 11(8): p. 1352-1367.

84. Cussler, E.L., Diffusion: mass transfer in fluid systems2009: Cambridge university press.

85. Adolfo Campos, C., Response of soil surface $\mathrm{CO}<\mathrm{sub}>2</ \mathrm{sub}>-\mathrm{C}$ flux to land use changes in a tropical cloud forest (Mexico). Forest ecology and management, 2006. 234(1): p. 305-312.

86. Bain, W.G., et al., Wind-induced error in the measurement of soil respiration using closed dynamic chambers. Agricultural and Forest Meteorology, 2005. 131(3): p. 225232.

87. Xu, L., et al. Critical Considerations for Accurate Soil CO2 Flux Measurement. 2005.

88. McDermitt, D.K., et al., Equalizing Pressures Between A Soil CO2 Flux Chamber and the Ambient Air Under Windy Conditions. LI-COR® Biosciences, 2005. 4421.

89. Suleau, M., et al., Wind velocity perturbation of soil respiration measurements using closed dynamic chambers. European Journal of Soil Science, 2009. 60(4): p. 515-524.

90. Hongxing, Z., et al., Multichannel automated chamber system for continuous monitoring of $\mathrm{CO} 2$ exchange between the agro-ecosystem or soil and the atmosphere. Acta Ecologica Sinica, 2007. 27(4): p. 1273-1281.

91. Sachs, T., et al., Methane emission from Siberian wet polygonal tundra on multiple spatial scales: vertical flux measurements by closed chambers and eddy covariance, Samoylov Island, Lena River Delta. 2008.

92. Stull, R.B., Meteorology for scientists and engineers: a technical companion book with Ahrens' Meteorology Today2000: Brooks/Cole.

93. Kaviany, M., Principles of heat transfer in porous media2012: Springer Science \& Business Media. 
94. PAVELKA, M., et al., Chamber techniques versus eddy covariance method during nighttime measurements.

95. Najafpour, G., Biochemical engineering and biotechnology2015: Elsevier.

96. Couwenberg, J., R. Dommain, and H. Joosten, Greenhouse gas fluxes from tropical peatlands in south-east Asia. Global Change Biology, 2010. 16(6): p. 1715-1732.

97. Hillel, D., Soil and water: physical principles and processes1971: Academic Press.

98. Kindler, R., et al., Dissolved carbon leaching from soil is a crucial component of the net ecosystem carbon balance. Global Change Biology, 2011. 17(2): p. 1167-1185.

99. Sposito, G., The chemistry of soils2008: Oxford University Press, USA.

100. Conklin, A.R., Introduction to soil chemistry: Analysis and instrumentation. Vol. 167. 2005: John Wiley and Sons.

101. Suh, S.U., et al., A chamber system with automatic opening and closing for continuously measuring soil respiration based on an open-flow dynamic method. Ecological Research, 2006. 21(3): p. 405-414.

102. Risk, D., et al., Forced Diffusion soil flux: A new technique for continuous monitoring of soil gas efflux. Agricultural and Forest Meteorology, 2011.

103. Liu, X., et al., A survey on gas sensing technology. Sensors, 2012. 12(7): p. 9635-9665.

104. Silva, J., P. Feijóo, and R. Santos, Underwater measurements of carbon dioxide evolution in marine plant communities: A new method. Estuarine, Coastal and Shelf Science, 2008. 78(4): p. 827-830.

105. Lai, D., et al., The effect of atmospheric turbulence and chamber deployment period on autochamber $\mathrm{CO} 2$ and $\mathrm{CH} 4$ flux measurements in an ombrotrophic peatland. Biogeosciences, 2012. 9(8): p. 3305-3322. 
106. $\mathrm{Xu}, \mathrm{L}$. , et al., On maintaining pressure equilibrium between a soil $\mathrm{CO} 2$ flux chamber and the ambient air. Journal of Geophysical Research: Atmospheres (1984-2012), 2006. 111(D8).

107. Ngao, J., et al., Cross-calibration functions for soil $\mathrm{CO}$ efflux measurement systems. Annals of forest science, 2006. 63(5): p. 477-484.

108. Heinemeyer, A., et al., Soil respiration: implications of the plant-soil continuum and respiration chamber collar-insertion depth on measurement and modelling of soil $\mathrm{CO} 2$ efflux rates in three ecosystems. European journal of soil science, 2011. 62(1): p. 8294.

109. Sah, R.L.Y., et al., Biosynthetic response of cartilage explants to dynamic compression. Journal of Orthopaedic Research, 1989. 7(5): p. 619-636.

110. Healy, R.W., et al., Numerical Evaluation of Static-Chamber Measurements of SoilAtmosphere Gas Exchange: Identification of Physical Processes. Soil Science Society of America Journal, 1996. 60(3): p. 740-747.

111. Nobuhiro, T., et al., Development of the IRGA enclosed-chamber system for soil CO2 efflux measurement and its application to a spatial variation measurement. Journal of Forest Research, 2003. 8(4): p. 297-301.

112. Aneja, V., et al., Dynamic Chamber System to Measure Gaseous Compounds Emissions and Atmospheric-Biospheric Interactions. Environmental simulation chambers: application to atmospheric chemical processes, 2006: p. 97-109.

113. Rochette, P., et al., Description of a dynamic closed chamber for measuring soil respiration and its comparison with other techniques. Canadian journal of soil science, 1997. 77(2): p. 195-203.

114. Jassal, R., et al., Relationship between soil CO2 concentrations and forest-floor CO2 effluxes. Agricultural and Forest Meteorology, 2005. 130(3): p. 176-192. 
115. Parkin, T.B. and R.T. Venterea, USDA-ARS GRACEnet Project Protocols Chapter 3. Chamber-Based Trace Gas Flux Measurements 4. Book Chapter, 2010: p. 1-39.

116. Buchmann, N., Biotic and abiotic factors controlling soil respiration rates in Picea abies stands. Soil Biology and Biochemistry, 2000. 32(11): p. 1625-1635.

117. Ngao, J., et al., Cross-calibration functions for soil $\mathrm{CO} \$_{-}\{2\} \$$ efflux measurement systems. Annals of forest science, 2006. 63(5): p. 477-484.

118. Reth, S., M. Reichstein, and E. Falge, The effect of soil water content, soil temperature, soil pH-value and the root mass on soil CO 2 efflux-a modified model. Plant and Soil, 2005. 268(1): p. 21-33.

119. Program, U.o.N.L.T.S. Soil Testing for Turf Areas. 2012 30/10/2012]; Available from: http://turf.unl.edu/pdfcaextpub/SoilTesting2012g.pdf.

120. $\mathrm{Xu}, \mathrm{M}$. and Y. Qi, Soil-surface CO2 efflux and its spatial and temporal variations in a young ponderosa pine plantation in northern California. Global Change Biology, 2001. 7(6): p. 667-677.

121. Hoorman, J.J., The Role of Soil Bacteria. 2011.

122. Jobbágy, E.G. and R.B. Jackson, The distribution of soil nutrients with depth: global patterns and the imprint of plants. Biogeochemistry, 2001. 53(1): p. 51-77.

123. Gagliardi, J.V. and J.S. Karns, Leaching of Escherichia coli O157: H7 in diverse soils under various agricultural management practices. Applied and environmental microbiology, 2000. 66(3): p. 877-883.

124. Singh, O., et al., Phytoremediation: an overview of metallic ion decontamination from soil. Applied Microbiology and Biotechnology, 2003. 61(5-6): p. 405-412.

125. Silver, S. and L.T. Phung, A bacterial view of the periodic table: genes and proteins for toxic inorganic ions. Journal of Industrial Microbiology and Biotechnology, 2005. 32(11-12): p. 587-605. 
126. Duval, B.D., et al., Plant- Soil Distribution of Potentially Toxic Elements in Response to Elevated Atmospheric CO2. Environmental science \& technology, 2011. 45(7): p. $2570-2574$.

127. Wong, M. and A. Bradshaw, A comparison of the toxicity of heavy metals, using root elongation of rye grass, Lolium perenne. New Phytologist, 1982. 91(2): p. 255-261.

128. Uchida, M., et al., Contribution of micro-organisms to the carbon dynamics in black spruce (Picea mariana) forest soil in Canada. Ecological Research, 1998. 13(1): p. 1726.

129. Wood, C., et al., Free-air CO2 enrichment effects on soil carbon and nitrogen. Agricultural and Forest Meteorology, 1994. 70(1-4): p. 103-116.

130. Monon, J., The growth of bacterial cultures. Selected Papers in Molecular Biology by Jacques Monod, 2012: p. 139.

131. Ferenci, T., Growth of bacterial cultures' 50 years on: towards an uncertainty principle instead of constants in bacterial growth kinetics. Research in microbiology, 1999. 150(7): p. 431-438.

132. Shuler, M.L. and F. Kargi, Bioprocess engineering2002: Prentice Hall New York.

133. Valarini, P.J., et al., Integrated evaluation of soil quality after the incorporation of organic matter and microorganisms. Brazilian Journal of microbiology, 2002. 33(1): p. 35-40.

134. Ratkowsky, D., et al., Relationship between temperature and growth rate of bacterial cultures. Journal of Bacteriology, 1982. 149(1): p. 1-5.

135. Ratkowsky, D., et al., Model for bacterial culture growth rate throughout the entire biokinetic temperature range. Journal of Bacteriology, 1983. 154(3): p. 1222-1226.

136. Madenjian, C.P., Nighttime pond respiration rate: oxygen or temperature dependent? Canadian Journal of Fisheries and Aquatic Sciences, 1990. 47(1): p. 180-183. 
137. Ann McCauley, S.S., Clain Jones, Extension Soil Fertility Specialist and Jeff Jacobsen, Soil Scientist. BASIC SOIL PROPERTIES. Soil and water managment module 12005 13/08/2012]; Available from: http://landresources.montana.edu/SWM/PDF/Final_proof_SW1.pdf.

138. Papendick, R. and G. Campbell, Theory and measurement of water potential. Water potential relations in soil microbiology, 1981. 3: p. 1-22.

139. Abbott, L.K. and D.V. Murphy, Soil Biological Fertility: A Key to Sustainable Land Use in Agriculture2003: Kluwer Academic Publishers.

140. Füllner, K., The influence of spatially heterogeneous soil temperatures on plant structure and function. Vol. 76. 2007: Forschungszentrum Jülich.

141. Nepstad, D., et al., The effects of partial throughfall exclusion on canopy processes, aboveground production, and biogeochemistry of an Amazon forest. Journal of Geophysical Research: Atmospheres (1984-2012), 2002. 107(D20): p. LBA 53-1-LBA 53-18.

142. Gaumont-Guay, D., et al., Interpreting the dependence of soil respiration on soil temperature and water content in a boreal aspen stand. Agricultural and Forest Meteorology, 2006. 140(1): p. 220-235.

143. Havlin, J., et al., Soil fertility and fertilizers: An introduction to nutrient management. Vol. 515. 2005: Pearson Prentice Hall Upper Saddle River, NJ.

144. Troeh, F.R. and L.M. Thompson, Soils and soil fertility2005: Blackwell Iowa. 